ISSN 2075-4701

www.mdpi.com/journal/metals/

Article

\title{
Role of Alloying Additions in the Solidification Kinetics and Resultant Chilling Tendency and Chill of Cast Iron
}

\author{
Edward Fraś ${ }^{1, \uparrow}$, Hugo F. Lopez ${ }^{2, *}$, Magdalena Kawalec ${ }^{1}$ and Marcin Gorny ${ }^{1}$
}

1 Foundry Institute, AGH University of Science and Technology, Reymonta 23, Cracow 30-059, Poland; E-Mails: kawalec@agh.edu.pl (M.K.); mgorny@agh.edu.pl (M.G.)

2 Department of Materials Science and Engineering, University of Wisconsin Milwaukee, 3200 N. Cramer Street, Milwaukee, WI 53211, USA

$\dagger \quad$ Edward Fras recently passed away on 15 January 2013.

* Author to whom correspondence should be addressed; E-Mail: hlopez@uwm.edu; Tel.: +1-414-229-6005.

Academic Editor: Anders E. W. Jarfors

Received: 10 January 2015 / Accepted: 25 February 2015 / Published: 4 March 2015

\begin{abstract}
The present work describes the effect of the solidification processing and alloy chemistry on the chilling tendency index, CT, and the chill, w, of wedge-shaped castings made of cast iron. In this work, theoretical predictions were experimentally verified for the role of elements, such as $\mathrm{C}, \mathrm{Si}, \mathrm{Mn}, \mathrm{P}$ and $\mathrm{S}$, on the cast iron $\mathrm{CT}$. In addition, inoculation and fading effects were considered in the experimental outcome. Accordingly, the graphite nucleation coefficients, $\mathrm{N}_{\mathrm{s}}, \mathrm{b}$, the eutectic cell growth coefficient, $\mu$, and the critical cooling rate, $\mathrm{Q}_{\mathrm{cr}}$, for the development of eutectic cementite (chill) were all determined as a function of the cast iron chemistry and time after inoculation. In particular, it was found that increasing the $\mathrm{Mn}$ and $\mathrm{S}$ contents, as well as the time after inoculation lowers the critical cooling rate, thus increasing the chilling tendency of the cast iron. In contrast, $\mathrm{C}, \mathrm{Si}$ and $\mathrm{P}$ increase the critical cooling rate, and as a result, they reduce the cast iron CT and chill.
\end{abstract}

Keywords: chill; chilling tendency; gray cast iron; role of $\mathrm{C}$; $\mathrm{Si}$; $\mathrm{Mn}$; $\mathrm{P}$; $\mathrm{Mn}$; inoculation effects 


\section{Introduction}

One of the important indices that accounts for the quality of cast iron is its chilling tendency, that is its tendency to solidify according to the Fe-C-X metastable system. The chilling tendency, CT, depends on the physical-chemical state of the liquid iron, while the chill (the fraction of eutectic cementite in the casting) formation depends additionally on the casting cooling rate. In foundry practice, the CT for the various types of cast iron is determined from comparisons of the exhibited fraction of eutectic cementite (chill) in castings solidified under similar cooling rates. Based only on these comparisons, the difference in the chilling tendency for various cast irons can be established, but the absolute CT values for given irons cannot be disclosed [1].

It is well known that the chilling tendency of cast irons determines their subsequent performance in diverse applications. In particular, cast irons possessing a high CT tend to develop zones of white or mottled iron. Considering that these regions can be extremely hard, their machinability can be severely impaired. Alternatively, if white iron is the desired structure, a relatively small chilling tendency will favor the formation of gray iron. This, in turn, leads to low hardness and poor wear properties in as-cast components. Hence, considerable efforts [1-7] have been made to correlate the inoculation practice, iron composition, pouring temperature, etc., with the cast iron CT.

In the published literature, there are only a few attempts aimed at elucidating the mechanisms responsible for the chill of cast iron [3,8-11]. Besides, none of the proposed hypotheses take into account the complexity of the solidification process. In most cases, the proposed theories assume that a single factor is the determinant in establishing the final solidification structure, while the remaining factors are ignored. In addition, various numerical models have been proposed [12,13] to predict whether a given casting or a part of it will solidify according to the stable or metastable Fe-C-X system. Yet, their application is tedious due to extensive numerical calculations. Accordingly, in this work, a simple analytical model is employed to account for the mechanism or mechanisms responsible for the CT of cast iron and, hence, the exhibited chill.

\subsection{Analysis}

During cast iron solidification, two processes become relevant: (a) nucleation; and (b) growth of eutectic cells, which have a direct effect on the final microstructure.

(a) Nucleation of eutectic cells

In liquid-solid transformations, nucleation is heterogeneous in nature. Accordingly, a simple model for heterogeneous nucleation of graphite in cast iron has recently been proposed [14], which describes the nucleation of eutectic cells, $\mathrm{N}$, by the following expression:

$$
N=N_{\mathrm{s}} \exp \left(-\frac{b}{\Delta T_{\mathrm{m}}}\right)
$$

and

$$
\Delta T_{\mathrm{m}}=T_{\mathrm{s}}-T_{\mathrm{m}}
$$


where $N_{\mathrm{s}}$ and $b$ are the nucleation coefficients, $\Delta T_{\mathrm{m}}$ is the maximum degree of undercooling at the onset of graphite eutectic solidification, $T_{\mathrm{s}}$ is the graphite eutectic equilibrium temperature and $T_{\mathrm{m}}$ is the minimal temperature at the onset of graphite eutectic solidification (see Figure 1).

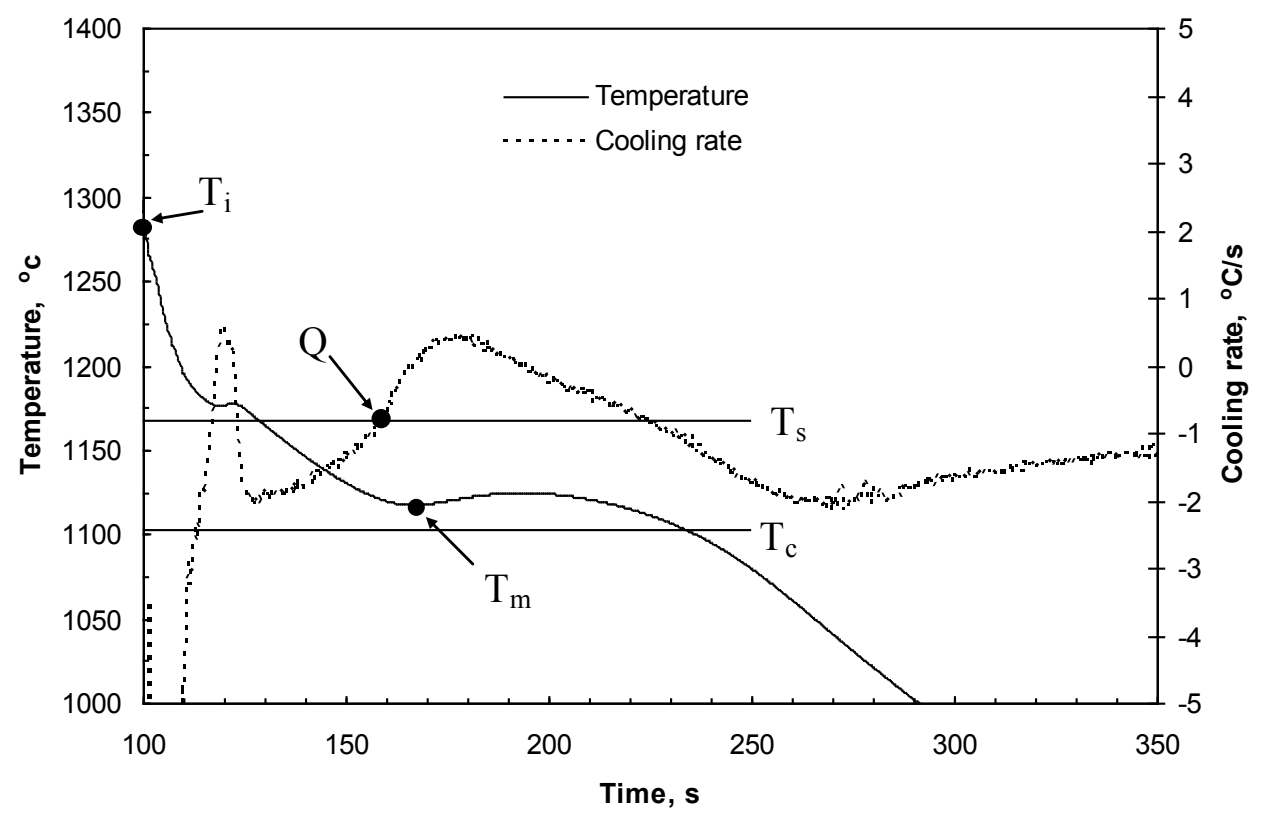

Figure 1. Cooling curves and cooling rate curves for cast iron. $T_{\mathrm{i}}=$ initial temperature of the metal in the mold cavity just after pouring; $T_{\mathrm{s}}=$ graphite eutectic equilibrium temperature; $T_{\mathrm{c}}=$ cementite equilibrium temperature; $T_{\mathrm{m}}=$ minimal temperature; and $\mathrm{Q}=$ cooling rate of cast iron at the onset of graphite eutectic solidification.

It is well known that each graphite nucleus gives rise to a single eutectic cell. Hence, it can be assumed that a measure of the graphite nuclei density is given by measurements of the eutectic cell count (cells/volume). Thus, the eutectic cell count can be related to the graphite nucleation potential through Equation (1), where the melt is characterized by the nucleation coefficients, $N_{\mathrm{s}}$, and $b$.

(b) The growth rate of eutectic cells can be described by [15]:

$$
u=\mu \Delta T^{2}
$$

where $\mu$ is the growth coefficient of the eutectic cells and $\Delta T$ is the melt undercooling.

\subsection{Onset of Graphite Eutectic Solidification}

The heat generated during the solidification of cast iron depends on both the cell count and the growth rate of the eutectic cells. Thus, by combining the heat extraction from the mold with the heat generated during the solidification of eutectic cells, the minimal temperature, $T_{\mathrm{m}}$ (Figure 1), or the maximum undercooling, $\Delta T_{\mathrm{m}}=T_{\mathrm{s}}-T_{\mathrm{m}}$, at the onset of graphite eutectic solidification can be determined from [4]:

$$
T_{\mathrm{m}}=T_{\mathrm{s}}-\Delta T_{\mathrm{m}}=T_{\mathrm{s}}\left[\frac{4 c_{e f} Q^{3}}{\pi^{3} L_{e} N \mu^{3} f}\right]
$$


where:

$$
\begin{gathered}
Q=\frac{2 T_{\mathrm{s}} a^{2}}{\pi \phi c_{e f} M^{2}} \\
c_{e f}=c+\frac{L_{\gamma}}{T_{1 \gamma}-T_{\mathrm{s}}} \\
\phi=c B+c_{e f} B_{1} \\
B=\ln \frac{T_{\mathrm{i}}}{T_{1}} ; B_{1}=\ln \frac{T_{1}}{T_{\mathrm{s}}}
\end{gathered}
$$

where $M$ is the casting modulus, $T_{i}$ is the initial liquid metal temperature just after pouring into the mold and $T_{1}, T_{\mathrm{l} \gamma}$, a, c, $L_{e}, L_{\gamma}$ and $\mathrm{f}$ are various solidification parameters, defined in Table 1.

Table 1. Selected thermophysical data [14]. C, Si, P: \% content of carbon, silicon and phosphorus in cast iron, respectively.

\begin{tabular}{cc}
\hline Parameter & Value and Units \\
\hline Latent heat of eutectic graphite & $L_{\mathrm{e}}=2,028.8 ; \mathrm{J} / \mathrm{cm}^{3}$ \\
Latent heat of austenite & $L_{\gamma}=1,904.4 ; \mathrm{J} / \mathrm{cm}^{3}$ \\
Specific heat of cast iron & $c=5.95 ; \mathrm{J} /\left(\mathrm{cm}^{3} \cdot{ }^{\circ} \mathrm{C}\right)$ \\
Material mold ability to absorb heat & $a=0.11 ; \mathrm{J} /\left(\mathrm{cm}^{2} \cdot \mathrm{s}^{1 / 2} \cdot{ }^{\circ} \mathrm{C}\right)$ \\
Liquidus temperature for pro-eutectic austenite & $T_{1}=1,636-113(\mathrm{C}+0.25 \mathrm{Si}+0.5 \mathrm{P}) ;{ }^{\circ} \mathrm{C}$ \\
Carbon content in eutectic graphite & $C_{\mathrm{e}}=4.26-0.30 \mathrm{Si}-0.36 \mathrm{P} ; \%$ \\
Maximum carbon content in austenite at $T_{\mathrm{s}}$ & $C_{\gamma}=2.08-0.11 \mathrm{Si}-0.35 \mathrm{P} ; \%$ \\
Liquidus temperature of pre-eutectic austenite when & $T_{l_{\gamma}}=1,636-113(2.08+0.15 \mathrm{Si}+0.14 \mathrm{P}) ;{ }^{\circ} \mathrm{C}$ \\
its composition is $C_{\gamma}$ & $g_{\gamma}=\left(C_{\mathrm{e}}-C\right) /\left(C_{\mathrm{e}}-C_{\gamma}\right)$ \\
Weight fraction of austenite cast iron at the beginning & $\rho_{\gamma}=7.51 \mathrm{~g} / \mathrm{cm}^{3}$ \\
of eutectic solidification & $\rho_{l}=7.1 \mathrm{~g} / \mathrm{cm}^{3}$ \\
Austenite density & $f=\rho_{\gamma} \mathrm{g}_{l} /\left[\rho_{\gamma} \mathrm{g}_{l}+\rho_{l}\left(1-\mathrm{g}_{l}\right)\right]$ \\
Liquid cast iron density &
\end{tabular}

Combining Equations (1) and (4) yields:

$$
\Delta T_{m}=T_{s}-T_{m}=\frac{b}{\text { 8ProductLog }[y]}
$$

where:

ProductLog $[y]=x$ is the Lambert function (see http://mathworld.wolfram.com./LambertW-function. $\mathrm{html}$ ), also known as the omega function, graphically shown in Figure 2. This function can be easily calculated by means of the instruction ProductLog $[y]$ in the Mathematica ${ }^{\mathrm{TM}}$ program.

Additionally:

$$
y=\frac{b}{82^{1 / 4}}\left[\frac{\pi^{3} \operatorname{Le~}_{\mathrm{s}} \mu^{3} f}{c_{e f} Q^{3}}\right]^{1 / 8}
$$


Combining Equations (1) and (9), the spatial cell count can be determined from:

$$
N=\frac{N_{\mathrm{s}}}{\exp [8 \operatorname{Product} \log (y)]}
$$

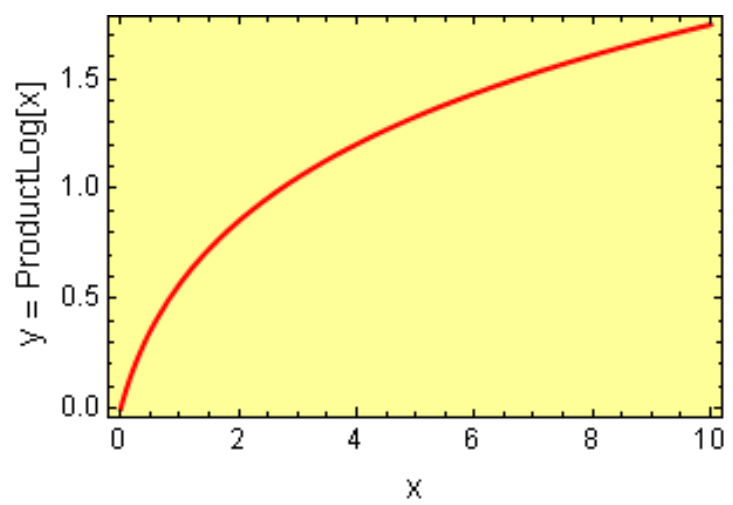

Figure 2. Graphic representation of the ProductLog $[y]$ function for $y \geq 0$.

\subsection{Chilling Tendency Index}

Figure 3 shows the cooling curves with the $\mathrm{T}_{\mathrm{m}}$ values, including the eutectic graphite and $\mathrm{N}$ along the wedge axis for two solidified cast irons with different physical-chemical states. The temperature range $\Delta T_{\mathrm{sc}}=T_{\mathrm{s}}-T_{\mathrm{c}}$ is also given in Figure 3. Notice that in the temperature range $\Delta T_{\mathrm{sc}}=T_{\mathrm{s}}-T_{\mathrm{c}}$, eutectic graphite is the only growing structure (gray cast iron). From this figure, it is apparent that increasing $Q$ to values equal to $Q_{\text {cr }}$ leads to an increase of eutectic cells from $N$ to $N_{\text {cr. Below }} T_{\text {c }}$, both graphite and eutectic cementite grow simultaneously, interfering with each other and giving rise to mottled cast iron. Accordingly, $T_{\mathrm{c}}$ can be considered as the transition temperature for the solidification of eutectic cementite from eutectic graphite or the chill formation temperature. From this figure, it is apparent that an increase of the cooling rate from $Q$ to $Q_{\mathrm{cr}}$ leads to a reduction in $T_{\mathrm{m}}$ to $T_{\mathrm{c}}$ and, hence, to the formation of eutectic cementite (chill development). Thus, determination of the critical cooling rate, $Q_{\text {cr, }}$ is key in establishing the critical conditions for the development of eutectic cementite (chill) in castings.

When $Q=Q_{\mathrm{cr}}$ or $M=M_{\mathrm{cr}}$ and $\Delta T_{\mathrm{m}}=\Delta T_{\mathrm{sc}}$ (Figure 3), the critical cooling rate can be estimated from Equations (1) and (4) as:

$$
Q_{\mathrm{cr}}=\pi \mu\left[\frac{L_{e} N_{\mathrm{s}} f \Delta T_{\mathrm{sc}}^{8}}{4 c_{e f}} \exp \left(-\frac{b}{\Delta T_{\mathrm{sc}}}\right)\right]
$$

Taking into account Equations (1) and (4) (for $\Delta T_{\mathrm{m}}=\Delta T_{\mathrm{m}}$ ) and (5), the critical casting modulus, $\mathrm{M}_{\mathrm{cr}}$, under which it is possible to develop a chill yields:

$$
M_{\mathrm{cr}}=p C T
$$

where:

$$
p=\frac{a}{\pi}\left(\frac{32 T_{\mathrm{s}}^{3}}{L_{e} c_{e f}^{2} \phi 3}\right)^{1 / 6}
$$


and:

$$
C T=\left[\frac{1}{N_{\mathrm{s}} f \mu^{3} \Delta T_{\mathrm{sc}}^{8}} \exp \left(\frac{b}{\Delta T_{\mathrm{sc}}}\right)\right]^{1 / 6}
$$

Notice from Equation (15) that $\mu, f, N_{\mathrm{s}}$ and $\Delta T_{\mathrm{sc}}$ all decrease $C T$, while b has the opposite effect.

a)

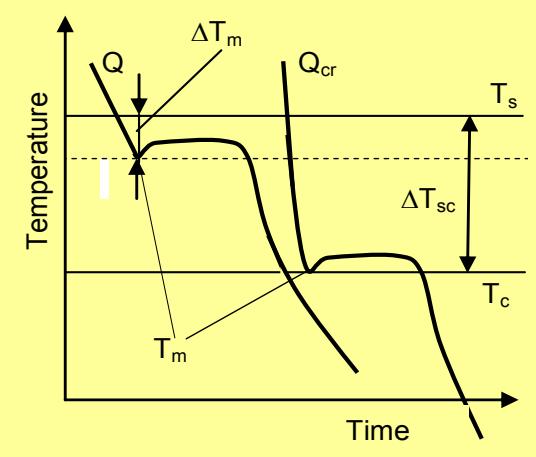

a)

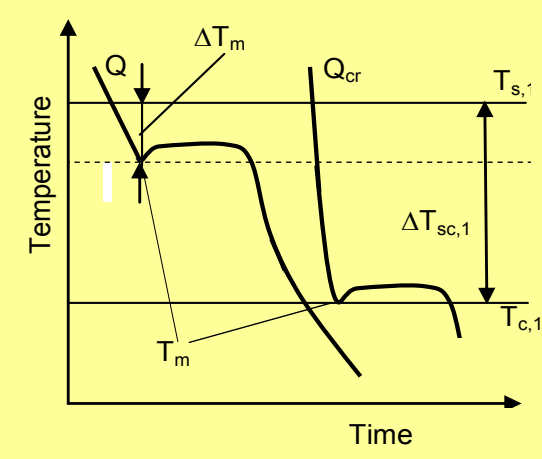

b)

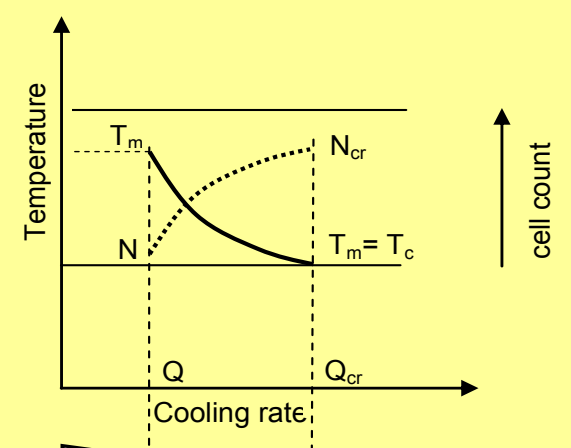

c)

c)

b)

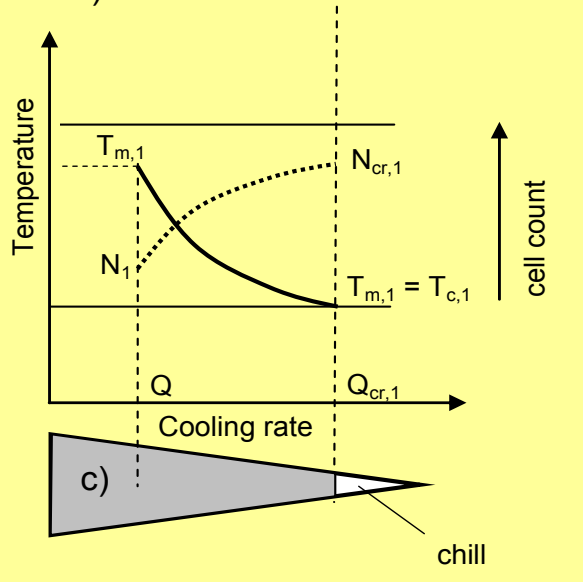

Figure 3. (a) Cooling curves and (b) effect of the cooling rate, $Q$, along the wedge axis on minimum solidification temperature, $T_{\mathrm{m}}$, eutectic graphite and eutectic cell count, $N$, for two cast irons with different physical-chemical properties. (c) Scheme of a wedge section containing a chill.

\subsection{Chill}

In foundry practice, an assessment of the chilling tendency of cast iron is based on the chill test methods established by the ASTM A367-55T standard. In this case, wedge geometries are employed (Figure 4a). As a first approximation, it is assumed that the geometrical casting modulus, $M_{\mathrm{w}}$, of a wedge can be estimated by: 


$$
\begin{gathered}
M_{\mathrm{w}}=\frac{\mathrm{F}_{\mathrm{ch}}}{m}=\frac{\frac{1}{2} h \frac{\mathrm{w}}{2}}{\frac{h}{\cos (\beta / 2)}}=\mathrm{w} \frac{\cos (\beta / 2)}{4} \\
M_{\mathrm{cr}}=p ; C T=M_{\mathrm{w}}
\end{gathered}
$$

In the above expression, $\beta$ is the wedge angle, $F_{c h}$ is the half surface area chill triangle and $h_{c r}$ and $m$ are the critical chill height and length (Figure 4a). Taking into account Equations (14) and (17), an expression is found that relates $\mathrm{M}_{\mathrm{cr}}$ to $\mathrm{M}_{\mathrm{w}}$.

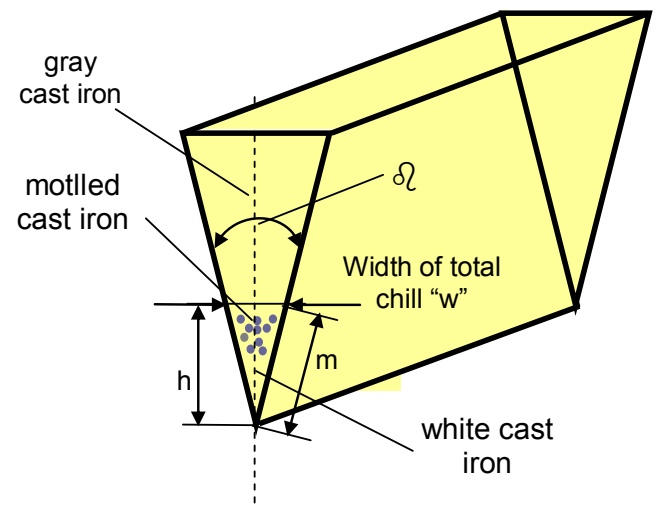

(a)

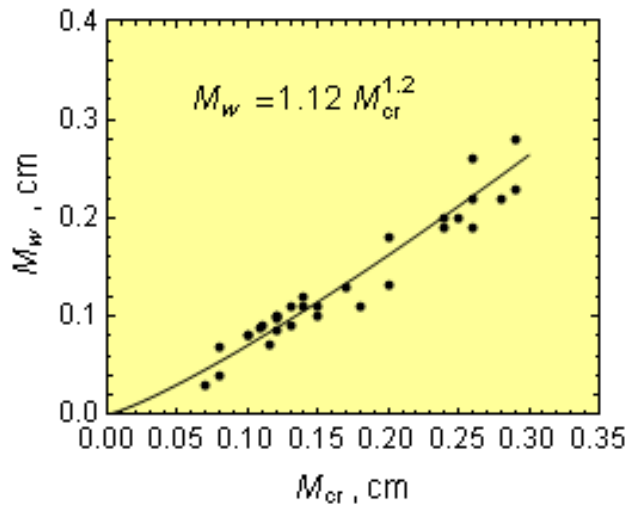

(b)

Figure 4. (a) Wedge geometry and (b) relationship between the casting modulus of the wedge with the critical casting modulus.

Nevertheless, the wedge cannot be considered as a simple body. The wedge thin sections are heated up from the thicker sections, and this is not taken into account in Equation (16). Accordingly, Equation (17) is corrected to reflect this effect. Considering the experimental $\mathrm{w}$ and $\beta$ values and plugging them into Equation (16), the modulus $M_{\mathrm{w}}$ can be estimated. Figure $4 \mathrm{~b}$ shows the relationship between the modulus $M_{\mathrm{w}}$ and $M_{\mathrm{cr}}$. Notice from this figure that $M_{\mathrm{w}} \neq M_{\mathrm{cr}}$ and that the function $M_{\mathrm{w}}=f\left(M_{\mathrm{cr}}\right)$ can be described by:

$$
M_{\mathrm{w}}=1.12 M_{\mathrm{cr}}^{1.2}
$$

Thus, by combining Equations (16) to (18), the "w" can be expressed as a function of the CT.

$$
w=\frac{4.46 p^{1.2}}{\cos (\beta / 2)} C T^{1.2}
$$

Notice that $\mathrm{w}$ depends additionally on the $\mathrm{p}$ coefficient, which includes parameters related to the cooling rate (Equation (4)), that is:

- The ability for the mold to absorb heat, a;

- The $\phi$ parameter, Equation (7), which depends on the B and $\mathrm{B}_{1}$ values (Equation (8)), that is on the initial temperature, $T_{\mathrm{i}}$, of the cast iron just after pouring the wedges. 
The effect of $T_{\mathrm{i}}$ and the ability of the wedge mold to absorb heat, a, on the p parameter is shown in Figure 5. Notice that the $\mathrm{p}$ parameter increases as the pouring temperature $T_{\mathrm{p}}$ (and, hence, $T_{\mathrm{i}}$ ) decreases, and the ability of the wedge mold to absorb heat increases. As a result, wedge removal at lower temperatures from molds with mold materials having an increasing ability to absorb heat, a (Table 2), leads to increasing chills in order to keep CT constant.

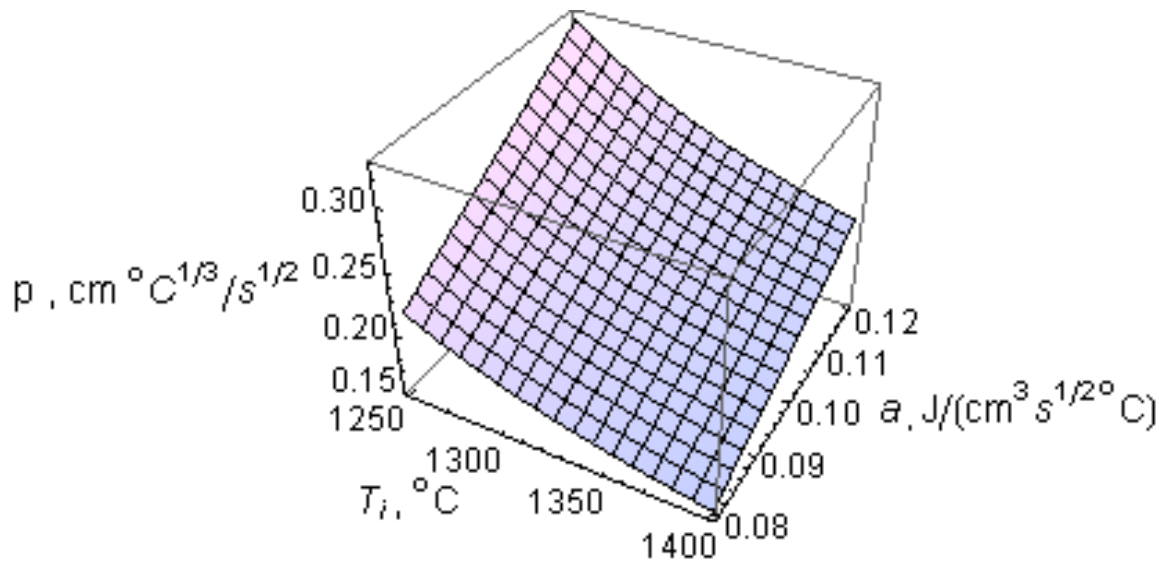

Figure 5. Effect of initial liquid metal temperature just after pouring into the mold, $\mathrm{T}_{\mathrm{i}}$, and the ability of the mold to absorb heat, a, on the p parameter.

Table 2. Reported a values for mold materials [11,16,17].

\begin{tabular}{cc}
\hline Mold Material & Material Mold Ability to Absorb Heat, $\mathbf{a}, \mathbf{J} /\left(\mathbf{c m}^{2} \cdot{ }^{\circ} \mathbf{C} \cdot \mathbf{s}^{\mathbf{1}}\right)$ \\
\hline Chromite & 0.15 \\
Zircon & $0.13-0.15$ \\
Quartz sand & $0.08-0.12$ \\
Olivine & 0.10 \\
Chemically-bonded urethane molding sand & $0.10-0.12$ \\
Chemically-bonded furan molding sand & $0.08-0.10$ \\
Chemically-bonded shell molding sand & $0.10-0.11$ \\
LDASC & $0.018-0.03$ \\
\hline
\end{tabular}

\section{Experimental Section}

Experimental melts were made in two stages. In the first stage, $40-\mathrm{mm}$ diameter bars containing pig iron and scrap steel were prepared. The scrap composition consisted of Sorelmetal $(4.27 \% \mathrm{C}$, $0.132 \% \mathrm{Si}, 0.13 \% \mathrm{Mn}, 0.026 \% \mathrm{P}, 0.005 \% \mathrm{~S})$ and steel scrap $(0.2 \% \mathrm{C}, 0.02 \% \mathrm{Si})$. In the second stage, the bars, together with various additives, such as carbon, $\mathrm{Si}, \mathrm{Fe}-\mathrm{P}$ and $\mathrm{Fe}-\mathrm{S}$, were charged into an induction furnace with a capacity of $1.5 \mathrm{~kg}$. Melting was carried out at low temperatures (i.e., below the equilibrium temperature for the $2 \mathrm{C}+\mathrm{SiO}_{2}=\mathrm{Si}+2 \mathrm{CO}$ reaction in order to avoid $\mathrm{C}$ losses as $\mathrm{CO}$ to the atmosphere [18]). In addition, low $\mathrm{S}$ and $\mathrm{Mn}$ contents were employed in order to minimize the formation of $\mathrm{MnS}$ compounds [19,20]. In this case, a manganese to sulfur ratio $(\mathrm{Mn} / \mathrm{S})$ of 1.7 was assumed to be "balanced" [20]. The aim of using these $\mathrm{Mn} / \mathrm{S}$ ratios was to investigate the effect of the excess $\mathrm{Mn}$ and $\mathrm{S}$ on the $\mathrm{CT}$ and chill. 
After melting and overheating to $1653 \mathrm{~K}\left(1380{ }^{\circ} \mathrm{C}\right)$, molten iron was cast into resin-bound foundry molds with bar shapes of 18 and $28 \mathrm{~mm}$ in diameter, as well as wedges (see Figure 6). From each melt, a sample was taken for chemical analysis.

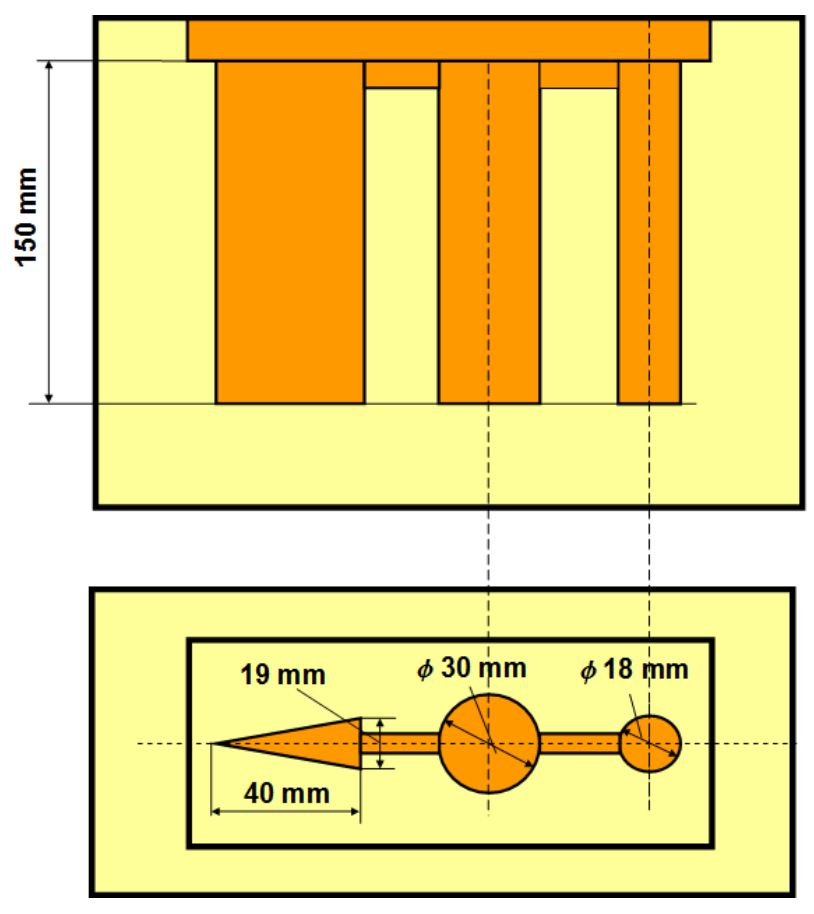

Figure 6. Mold for casting bars and wedges.

Pt-PtRh10 thermocouples were inserted in the center of the wedge and bar cavities of the sand molds. An Agilent 34970A electronic module was employed for numerical temperature recording. Figure 1 shows a typical cooling curve. The cooling curves were used for determinations of $T_{\mathrm{i}}$ just after filling the molds, $T_{\mathrm{m}}, \Delta T_{\mathrm{m}}=T_{\mathrm{s}}-T_{\mathrm{m}}$ and $\mathrm{Q}$ at the graphite eutectic equilibrium temperature, $T_{\mathrm{s}}$. After solidification, specimens for metallographic examination were taken from the wedges and bars. Metallographic examinations were made on specimen cross-sections. After etching the wedges (using nital), the width (w) of the total chill was measured at the gray cast iron-chilled iron intersections (see Figure 7). The wedges and bars were polished and etched using Stead reagent to reveal the graphite eutectic cell boundaries (Figure 7). Determinations of planar cell counts, NF, were made according to the so-called Variant II of the Jeffries method and by applying the Saltykov formula as an unbiased estimator for the rectangle of observation [21]:

$$
N_{\mathrm{F}}=\frac{N_{i}+0.5 N_{\mathrm{r}}+1}{F}
$$

where $N_{i}$ is the number of eutectic cells inside the measuring rectangle, $N_{\mathrm{r}}$ is the eutectic cell count that intersects the sides of the rectangle, but not its corners, and $F$ is the surface area of the rectangle. The graphite eutectic cells have a granular morphology; hence, it can be assumed that the spatial grain configurations follow the so-called Poisson-Voronoi model [22]. A stereological formula can then be used for determinations of the volumetric cell count $\mathrm{N}$, which yields the average number of eutectic cells per volume [22]. 


$$
N=0.568\left(N_{\mathrm{F}}\right)^{3 / 2}
$$

The cell count, $N_{\mathrm{F}, \mathrm{cr}}$, measured in wedges from the rectangular surface $F$ (Figure $7 \mathrm{a}$ ) at the gray cast iron-chilled iron intersections is considered as the critical cell count, $N_{\mathrm{F}, \mathrm{cr}}$, and it is converted into a volumetric cell count, $N_{\mathrm{cr}}$ (Equation (19)). An average of 10 readings was used per data point.

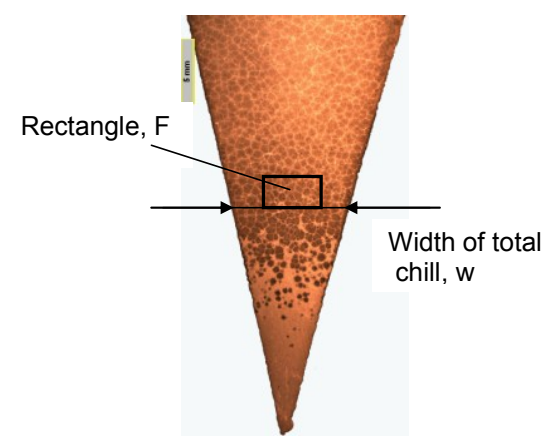

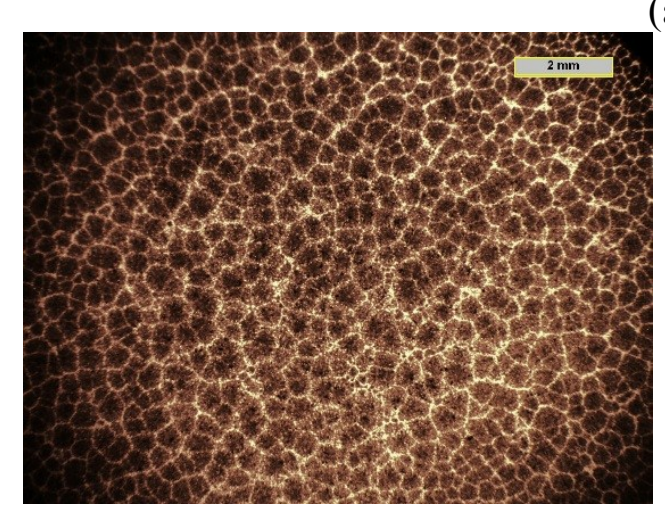

(b)

(a)

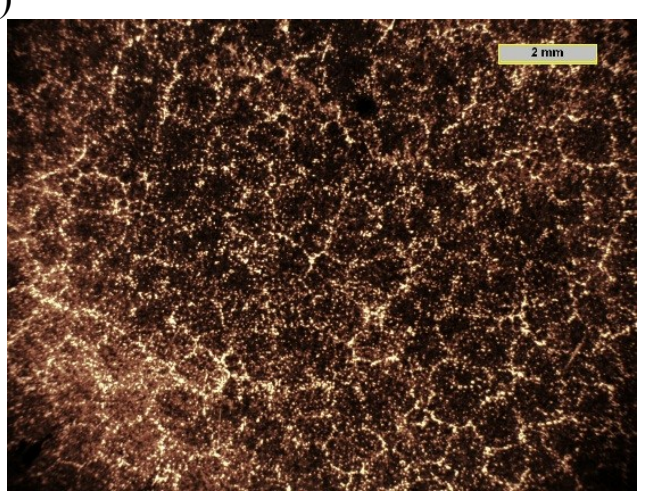

(c)

Figure 7. (a) Eutectic cells in a wedge-shaped casting; (b) bar $\phi 18 \mathrm{~mm}$ and (c) bar $\phi 28 \mathrm{~mm}$.

The experimental data and using Equation (1) in the logarithmic form yields:

$$
\ln N=\ln N_{s}-b \Delta T_{\mathrm{m}}^{-1}
$$

where the experimental points $\left(\Delta T_{\mathrm{m}, 1}, N_{1}\right),\left(\Delta T_{\mathrm{m}, 2}, N_{2}\right)$ and $\left(\Delta T_{\mathrm{sc}}, N_{\mathrm{cr}}\right)$ were determined for bars of 30 and $18 \mathrm{~mm}$ in diameter and wedges, respectively. The data are graphically plotted as a $\ln N-\Delta T_{\mathrm{i}}^{-1}$ plot (where $i=1,2, \mathrm{cr}$ ), and the data points fit a straight line (Figure 8). From this plot, experimental values of $N_{s}=\mathrm{e}^{11.9}=147,267 \mathrm{~cm}^{-3}$ and $b=97.1^{\circ} \mathrm{C}$ were obtained.

The growth coefficient for the experimental melts can be estimated as follows: for bars of diameter "d" and the length " $h$ ", the casting modulus can be given as:

$$
M=\frac{d h}{2(d+2 h)}
$$

Thus, for 1.8- and 3.0-cm diameter bars, the casting modulus is 0.42 and $0.65 \mathrm{~cm}$, respectively. In addition, considering Equations (3)-(5), $\mu$ can be determined from:

$$
\mu=\frac{2 T_{\mathrm{s}} a^{2}}{\pi^{2} \varphi M^{2}}\left[\frac{4}{\mathrm{f}_{1} \operatorname{Le} N c_{e f}^{2} \Delta T_{\mathrm{m}}^{8}}\right]^{1 / 3}
$$


Furthermore, knowing $M, T_{i}, N$ and $\Delta T_{\mathrm{m}}$, as well as the melt thermophysical data, the effect of C, $\mathrm{Mn}, \mathrm{P}$ and $\mathrm{S}$ on $\mu$ can be estimated from Equation (24). In this work, the initial calculations were made separately for 18 and $30 \mathrm{~mm}$ bars and then averaged out.

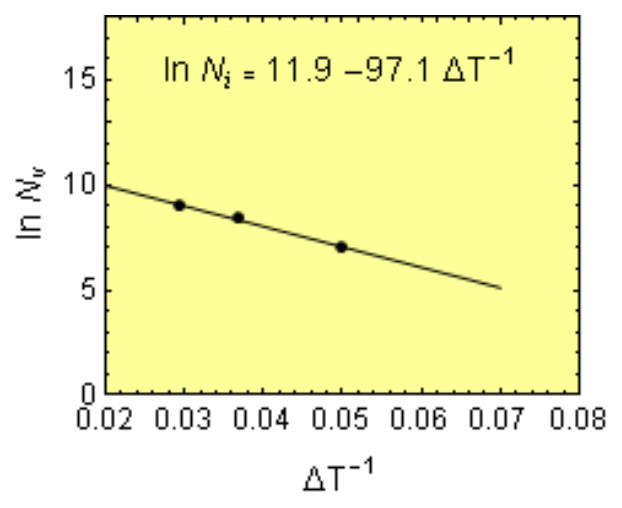

Figure 8. Relationship between undercooling, $\Delta T_{i}^{-1}$, and volumetric cell count, $\ln N_{i}$, for melt P1.

The temperature range, $\Delta T_{\mathrm{sc}}$, was estimated as follows: There have been numerous experimental investigations that have involved the determinations of $T_{\mathrm{c}}$ temperatures with variable results $[23,24]$, depending on the chemistry of the experimental iron melts. In fact, $T_{\mathrm{s}}$ is the equilibrium temperature when $Q \rightarrow 0$, making it difficult to determine. In this work, determination of the $T_{\mathrm{s}}$ temperature was possible by using selected thermodynamic data [25], as well as the work by Heine [26].

$$
T_{\mathrm{s}}=1154+5.25 \mathrm{Si}-2.36 \mathrm{Mn}-14.88 \mathrm{P}+35.0 \mathrm{~S}
$$

Furthermore, the $T_{\mathrm{c}}$ temperature can be described by [27]:

$$
T_{\mathrm{c}}=1130.0+4.0 \mathrm{C}-13.3 \mathrm{Si}-50.3 \mathrm{P}
$$

Hence:

$$
\Delta T_{\mathrm{sc}}=24-4.0 \mathrm{C}+18.6 \mathrm{Si}-2.3 \mathrm{Mn}+35.5 \mathrm{P}+35.0 \mathrm{~S}
$$

It is worth mentioning that in a binary eutectic $\mathrm{Fe}-\mathrm{C}$ alloy containing $4.26 \% \mathrm{C}$, Equations (25) and (16) yield $T_{\mathrm{s}}, T_{\mathrm{c}}$ and $\Delta T_{\mathrm{sc}}$ values of $1,427 \mathrm{~K}\left(1,154{ }^{\circ} \mathrm{C}\right), 1,420 \mathrm{~K}\left(1,147{ }^{\circ} \mathrm{C}\right)$ and $7 \mathrm{~K}\left(7^{\circ} \mathrm{C}\right)$, respectively, in agreement with the $\mathrm{Fe}-\mathrm{C}$ diagram.

\section{Results and Discussion}

\subsection{Nucleation Coefficients $N_{s}, b$}

Different particles with various sizes that act as graphite nucleation substrates are found to be present in cast iron melts. The type, number and size of these substrates are in general influenced by numerous factors, including the chemistry of the cast iron, inoculation, charge materials, melt precondition [28], temperature, bath holding times, furnace atmosphere and the type of slags. In general, the number of nucleation sites from these substrates can be described by the following size distribution function [29]: 


$$
n(l)=\frac{N_{\mathrm{s}}}{l_{\mathrm{a}}} \exp \left(-\frac{l}{l_{\mathrm{a}}}\right)
$$

where $N_{\mathrm{s}}$ and $l_{\mathrm{a}}$ are the number of all of the potential graphite nucleation sites in the melt and the average site size, respectively; $l$ is the size of the nucleation sites (Figure 9a). This function is schematically shown for two melt states $\mathrm{n}(l)$ and $\mathrm{n}_{\mathrm{i}}(l)$ (see Figure $9 \mathrm{~b}$ ). The number of all of the graphite nucleation sites in the melt is determined by the nucleation coefficient, $N_{\mathrm{s}}$ (i.e., the area under the $\mathrm{n}(l)$ and $\mathrm{n}_{\mathrm{i}}(l)$ curves for the $l_{\mathrm{min}}, l_{\mathrm{min}, 1}$ to $\infty$ range (Figure $9 \mathrm{~b}$ )). However, not all of the substrate sites take an active role in the nucleation process. The substrate site size, $l$, from which a nucleus of graphite can grow is determined by (see Figure 9a):

$$
\mathrm{AB}=l=2 \mathrm{r} * \sin \theta
$$

where $\theta$ is the wetting angle and $\mathrm{r}^{*}$ is the critical size of a graphite nucleus:

$$
r^{*} \geq \frac{2 \sigma T_{\mathrm{S}}}{\Delta H \Delta T}
$$

and $\sigma$ is the nucleus-melt interfacial energy, $\Delta H$ is the latent heat of solidification and $\Delta T$ is the degree of undercooling.

Taking into account Equations (29) and (30), the graphite substrate site size at a given undercooling, $\Delta T$, can be calculated from:

$$
l \geq \frac{4 \sigma T_{\mathrm{s}} \sin \theta}{\Delta H \Delta T}
$$

From Equation (31), it is found that as the undercooling, $\Delta T$, increases, the nucleation size, $l$, decreases. Figure 9c shows a cooling curve, $T(\mathrm{t})$, where the arrow indicates the maximum undercooling, $\Delta T_{\mathrm{m}}$. Notice that within the time interval $\mathrm{t}_{\mathrm{b}}$ to $\mathrm{t}_{\mathrm{m}}$ or $\Delta T=0$ to $\Delta T=\Delta T_{\mathrm{m}}$, all of the sites with $l_{\mathrm{m}} \leq l \leq \infty$ sizes become active for nucleation purposes. At the time $\mathrm{t}_{\mathrm{m}}$, the degree of undercooling drops, enabling graphite particles and substrates with $l \geq l_{\mathrm{m}}$ sizes to be active. In turn, this indicates that for $\mathrm{t}>\mathrm{t}_{\mathrm{m}}$, no active sites are present in the set of graphite substrates. As a result, any nucleation events stop at $\mathrm{t}_{\mathrm{m}}$. Thus, the number of active nucleation sites, $\mathrm{N}$, is given by the area below the $\mathrm{n}(l)$ curve in $l_{\mathrm{m}} \leq l \leq \infty\left(0 \leq \Delta T \leq \Delta T_{\mathrm{m}}\right)$. Plugging Equation (31) into Equation (28) and integrating from $l_{\mathrm{m}}$ to $\infty$, the second nucleation coefficient $b$ is obtained:

$$
b=\frac{4 T_{\mathrm{s}} \sigma \sin \theta}{l_{\mathrm{a}} \Delta H}
$$

The effect of the cast iron chemistry on $N_{\mathrm{s}}, \sigma, \theta$ and $l_{\mathrm{a}}$ is not known, and therefore, it is not possible to determine its effect on the nucleation coefficients $N_{\mathrm{s}}$ and $\mathrm{b}$. 

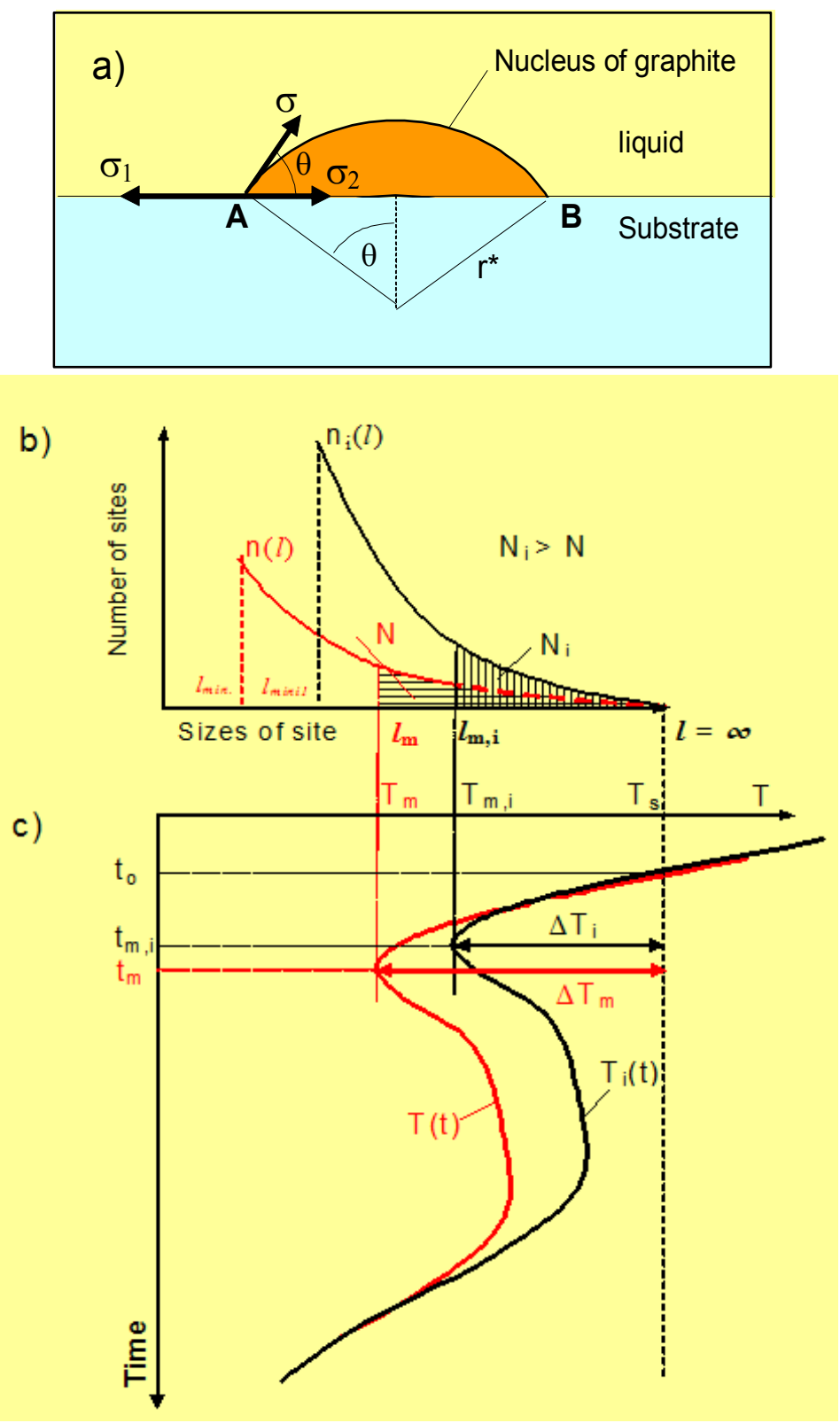

Figure 9. (a) Graphite nucleus on a substrate (b), size distribution for graphite nucleation sites and (c) cooling curves $T(l)$ and $T_{\mathrm{i}}(l)$ for two physical-chemical states of cast iron melts.

\subsection{The Growth Coefficient, $\mu$}

Little is known about $\mu$, and reported values for $\mu$ in pure $\mathrm{Fe}-\mathrm{C}$ and $\mathrm{Fe}-\mathrm{C}-\mathrm{X}$ alloys are given in Table 3 [30]. From this table, it is apparent that $\mu$ is highly sensitive to very small changes in the cast iron chemistry.

In Fe-C alloys, $\mu$ can be analytically derived [15], but the reported expressions are not simple. In general, $\mu$ is a constant depending on the composition of the cast iron [11] through: (1) the slope of the liquidus lines; (2) the volume fraction; (3) the Gibbs-Thomson coefficients for eutectic phases; (4) the contact angles between eutectic solid phases and the liquid; and (5) the liquid diffusivity. Unfortunately, there is a lack of information in the published literature on this subject. Thus, it is not possible to know the effect of the chemical composition on $\mu$. 
Table 3. Reported values for the eutectic growth coefficient, $\mu$ [30].

\begin{tabular}{lc}
\hline Alloy & Eutectic Growth Coefficient, $\mathbf{~ c m} /\left({ }^{\circ} \mathbf{C}^{2} \cdot \mathbf{s}\right)$ \\
\hline Fe-C & $9.18 \times 10^{-6}$ \\
Fe-C- $0.1 \% \mathrm{Si}$ & $7.30 \times 10^{-6}$ \\
Fe-C-0.5\% Si & $5.94 \times 10^{-6}$ \\
Fe-C-0.01\% P & $8.16 \times 10^{-6}$ \\
Fe-C-0.1\% P & $6.94 \times 10^{-5}$ \\
Fe-C-0.1\% Mn & $9.76 \times 10^{-6}$ \\
Fe-C- $0.6 \% \mathrm{Mn}$ & $1.47 \times 10^{-5}$ \\
Fe-C-0.005\% S & $7.30 \times 10^{-6}$ \\
Fe-C-0.01\% S & $5.94 \times 10^{-6}$ \\
\hline
\end{tabular}

\subsection{Effect of Carbon}

Table 4 shows the results on the exhibited $T_{\mathrm{i}}$ for various carbon contents in the experimental melts [11]. In addition, Figure 10 shows the exhibited $Q, \Delta T_{\mathrm{m}}$ and $N_{F}$ values.

Figure 10a shows the relationship between $Q$ and the $T_{\mathrm{s}}$ estimated from Equation (6), as well as the experimental outcome from the cooling curves. From this figure, it is apparent that carbon increases the cooling rate. This is a result of the carbon effect on lowering the liquidus temperature, $T_{1}$, which, in turn, reduces the $\mathrm{B}_{1}$ (Equation (8)) and $\phi$ (Equation (9)) values. Moreover, carbon increases the number of eutectic cells in the cast bars and wedges (Figure 10b) and reduces the undercooling (Figure 10c). Alternatively, the increase in cooling rates can be attributed to the increase in thermal conductivity associated with the increasing graphite content. These experimental correlations are described by regression equations for $N_{\mathrm{F}}, N_{\mathrm{F}, 1} N_{\mathrm{cr},} \Delta T_{\mathrm{m}}$ and $\Delta T_{\mathrm{m}, 1}$, and they are given in Table 4. Notice in particular that the experimental outcome is in good agreement with the predictions of Equations (5), (9) and (11).

Table 4. Carbon content in cast iron and experimental $T_{i}$ values.

\begin{tabular}{|c|c|c|c|c|}
\hline \multirow{2}{*}{ No. Melt * } & \multirow{2}{*}{$\mathrm{C}, \%$} & \multicolumn{3}{|c|}{ Initial Liquid Metal Temperature just after Pouring into the Mold, $T_{\mathrm{i}},{ }^{\circ} \mathrm{C}$} \\
\hline & & Bar $2.8 \mathrm{~cm}$ & Bar $1.8 \mathrm{~cm}$ & Wedge \\
\hline $\mathrm{C} 1$ & 3.06 & 1,375 & 1,251 & 1,250 \\
\hline $\mathrm{C} 2$ & 3.21 & 1,357 & 1,274 & 1,272 \\
\hline $\mathrm{C} 3$ & 3.42 & 1,335 & 1,260 & 1,272 \\
\hline $\mathrm{C} 4$ & 3.46 & 1,355 & 1,262 & 1,272 \\
\hline $\mathrm{C} 5$ & 3.48 & 1,352 & 1,263 & 1,276 \\
\hline $\mathrm{C} 6$ & 3.67 & 1,350 & 1,260 & 1,279 \\
\hline \multicolumn{2}{|c|}{ Cell count, $\mathrm{cm}^{-2}$} & bar $2.8 \mathrm{~cm}$ & \multicolumn{2}{|c|}{$N_{F}=2,730.6-1,653.9 \mathrm{C}+268.3 \mathrm{C}^{2}$} \\
\hline \multicolumn{2}{|c|}{ Cell count, $\mathrm{cm}^{-2}$} & bar $1.8 \mathrm{~cm}$ & \multicolumn{2}{|c|}{$N_{\mathrm{F} 1}=7,001.2-4,368.1 \mathrm{C}+723.4 \mathrm{C}^{2}$} \\
\hline \multicolumn{2}{|c|}{ Critical cell count } & & \multicolumn{2}{|c|}{$N_{\text {cr }}=-14,717+8,822.0 \mathrm{C}-1,232.5 \mathrm{C}^{2}$} \\
\hline \multicolumn{2}{|c|}{ Undercooling, ${ }^{\circ} \mathrm{C}$} & bar $2.8 \mathrm{~cm}$ & \multicolumn{2}{|c|}{$\Delta T_{\mathrm{m}}=63.9-13.0 \mathrm{C}$} \\
\hline \multicolumn{2}{|c|}{ Undercooling, ${ }^{\circ} \mathrm{C}$} & bar $1.8 \mathrm{~m}$ & \multicolumn{2}{|c|}{$\Delta T_{\mathrm{m}, 1}=-347.8+248.4 \mathrm{C}-40.3 \mathrm{C}^{2}$} \\
\hline \multicolumn{3}{|c|}{ Wedge width of the chill, $\mathrm{cm}$} & \multicolumn{2}{|c|}{$\mathrm{w}=3.05-0.66 \mathrm{C}$} \\
\hline \multicolumn{3}{|c|}{ Graphite eutectic growth coefficient, $\mu, \mathrm{cm} /\left(\mathrm{s}^{\circ}{ }^{\circ} \mathrm{C}^{2}\right)$} & \multicolumn{2}{|c|}{$\mu=10^{-5} \cdot\left(16.152-10.25 \mathrm{C}+1.644 \mathrm{C}^{2}\right)$} \\
\hline \multicolumn{5}{|c|}{ Nucleation coefficients } \\
\hline \multirow{2}{*}{\multicolumn{2}{|c|}{$\begin{array}{l}{ }^{\circ} \mathrm{C} \\
\mathrm{cm}^{-3}\end{array}$}} & & \multirow{2}{*}{\multicolumn{2}{|c|}{$\begin{array}{l}b=-574.73+501.33 \mathrm{Cz}-89.60 \mathrm{C}^{2} \\
N=10^{6} \cdot\left(-211+149 \mathrm{Cz}-0241 \mathrm{C}^{2}\right)\end{array}$}} \\
\hline & & & & \\
\hline
\end{tabular}

$* \mathrm{Si}=1.40 \%-1.46 \% ; \mathrm{Mn}=0.070 \%-0.076 \% ; \mathrm{P}=0.025 \%-0.034 \% ; \mathrm{S}=0.016 \%-0.019 \%$. 


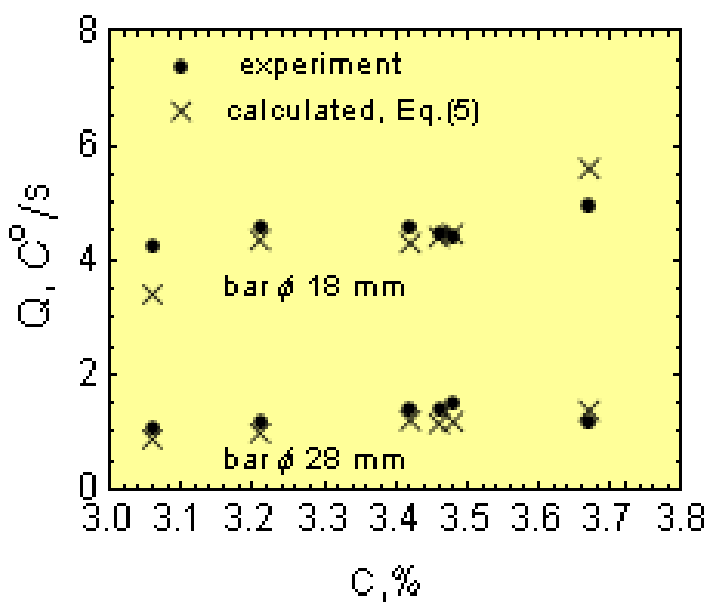

(a)

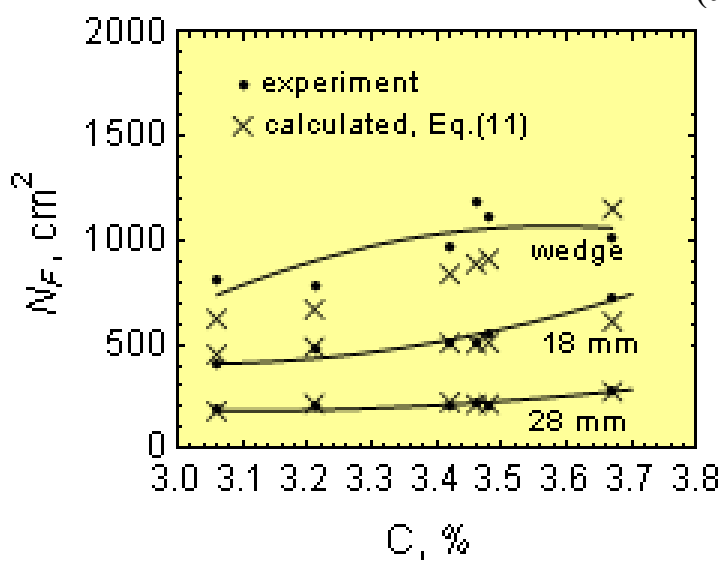

(b)

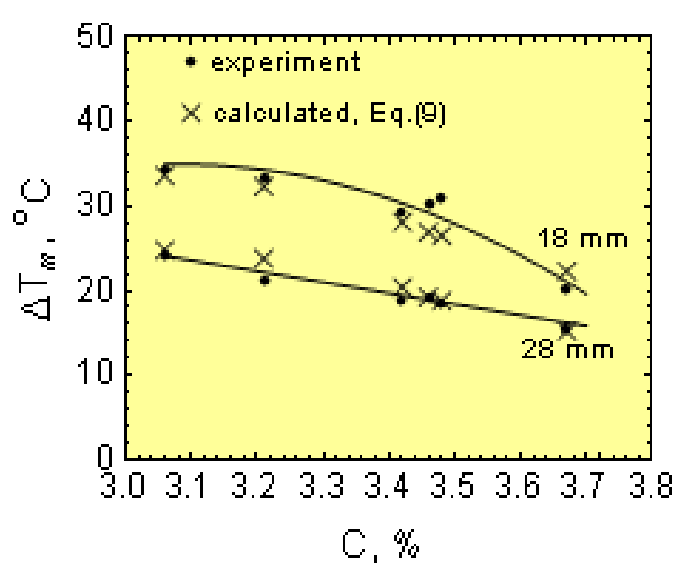

(c)

Figure 10. Effect of carbon on (a) the cooling rate, Q, of cast iron at the onset of solidification, (b) cell count and (c) undercooling.

Figure 11 shows the effect of carbon on the nucleation coefficients (Figure 11a,b) and on the graphite eutectic growth coefficient (Figure 11e). These correlations are described by regression expressions for $\mu, N_{s}$ and $\mathrm{b}$ in Table 4. Figure 11 also shows the volume fraction of liquid in the cast iron at the onset of eutectic solidification (Figure 11c) and the temperature range $\Delta T_{\mathrm{sc}}$ (Figure 11d). Notice from Figure 11 that carbon increases $N_{s}, \mu$ and $f$ while lowering b and $\Delta T_{\text {sc. }}$ As a result, carbon reduces the CT (Figure 11g) and increases $Q_{\text {cr }}$ (Figure 11f), thus reducing the chill (Figure 11g). Notice that the experimentally-determined chill width and the one predicted using Equation (4) are rather similar.

From the theory on eutectic growth [15] for pure Fe-C alloys, it is found that carbon does not have any influence on $\mu$. However, Figure 11e shows that carbon increases $\mu$. This can be explained by considering the segregation of Si during solidification. Silicon is soluble in austenite, and it progressively decreases in the liquid phase during the solidification of the pro-eutectic austenite. This agrees with reported data (Table 3) for $\mathrm{Si}$, which shows that as the $\mathrm{Si}$ content decreases, the graphite eutectic growth coefficient increases in magnitude. 


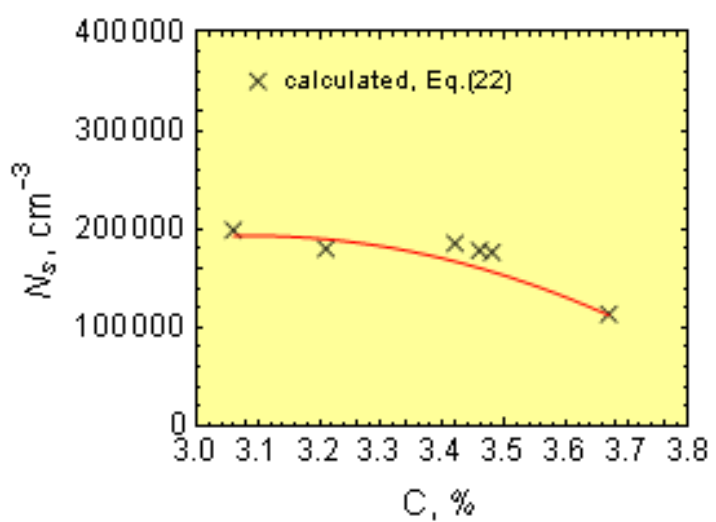

(a)

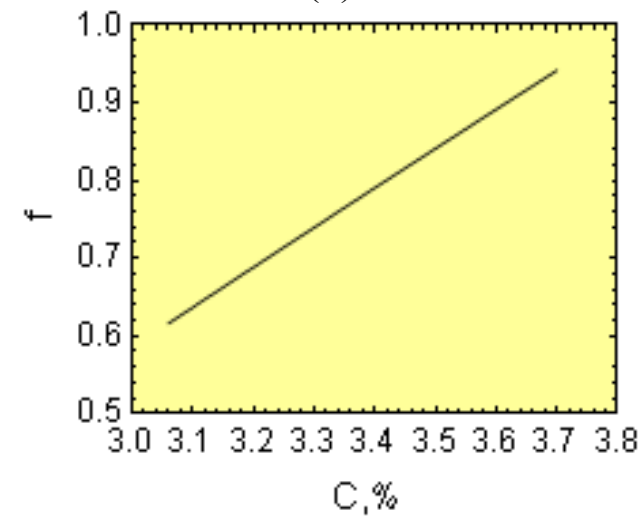

(c)

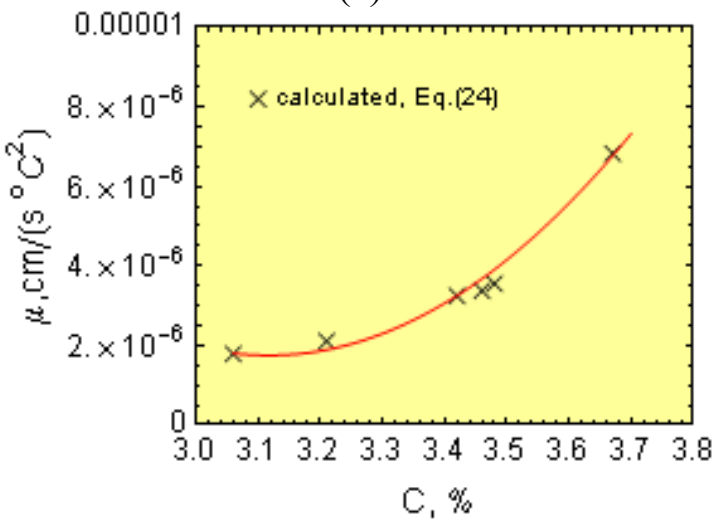

(e)

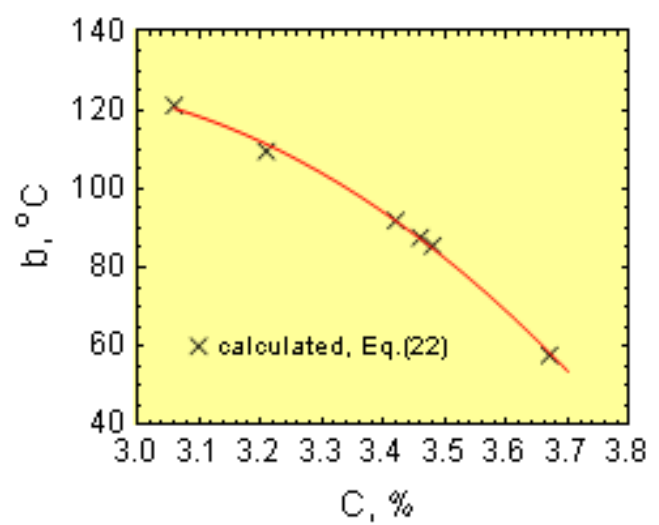

(b)

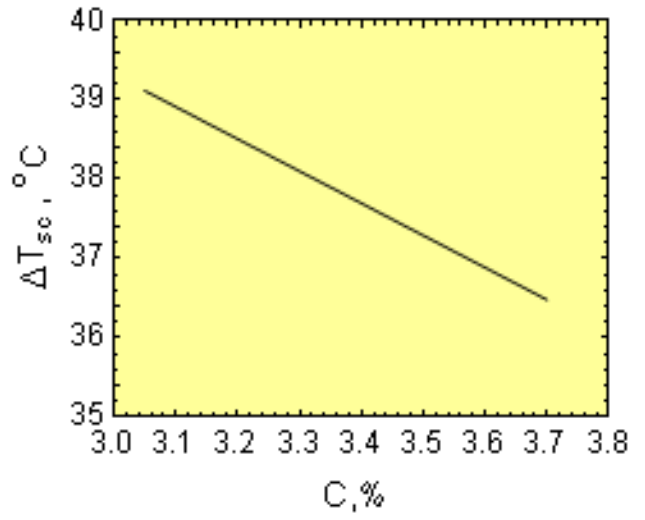

(d)

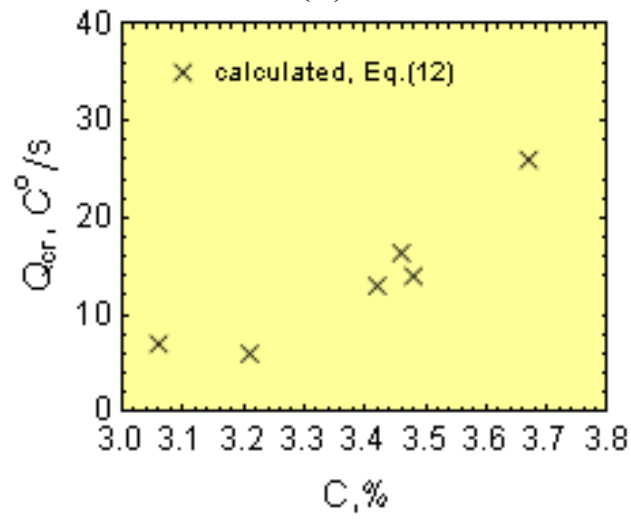

(f)

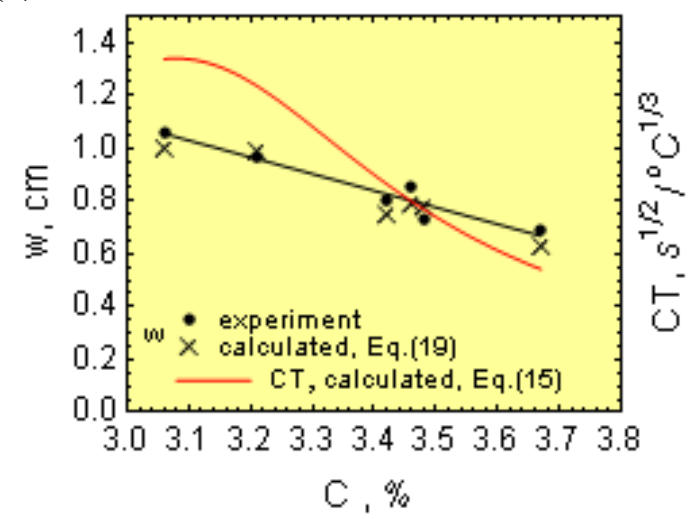

(g)

Figure 11. Effect of carbon on (a) $N_{s},(\mathbf{b}) b,(\mathbf{c}) f$, (d) $\Delta T_{\mathrm{sc}},(\mathbf{e}) \mu,(\mathbf{f}) Q_{\mathrm{cr}}$ and (g) the chilling tendency (CT) index and w. 
In order to establish the influence of carbon on the $\mathrm{CT}$, the following calculations were made. The $\mathrm{CT}$ was estimated for a carbon content $\mathrm{C}=3.06 \%$ using Equation (15) yielding a $\mathrm{CT}=1.21 \mathrm{~s}^{1 / 2} /{ }^{\circ} \mathrm{C}^{1 / 3}$. This value was assumed as a reference value. Next, calculations were made on CT values as they are influenced by carbon through $f, \mu, \Delta T_{\mathrm{sc}}, N_{s}$ and $b$. The results of these calculations were normalized to $100 \%$, and they are shown in Figure 12.

Notice from this figure that the intensity effect of carbon through $\mu$ on CT is very strong. When the carbon content increases, the influence of carbon on the CT through $\mu$ and $N_{s}$ increases, while it decreases through $\mathrm{b}$. In addition, the effect of carbon on $\mathrm{CT}$ through $f, \Delta T_{\mathrm{sc}}$, is almost balanced.

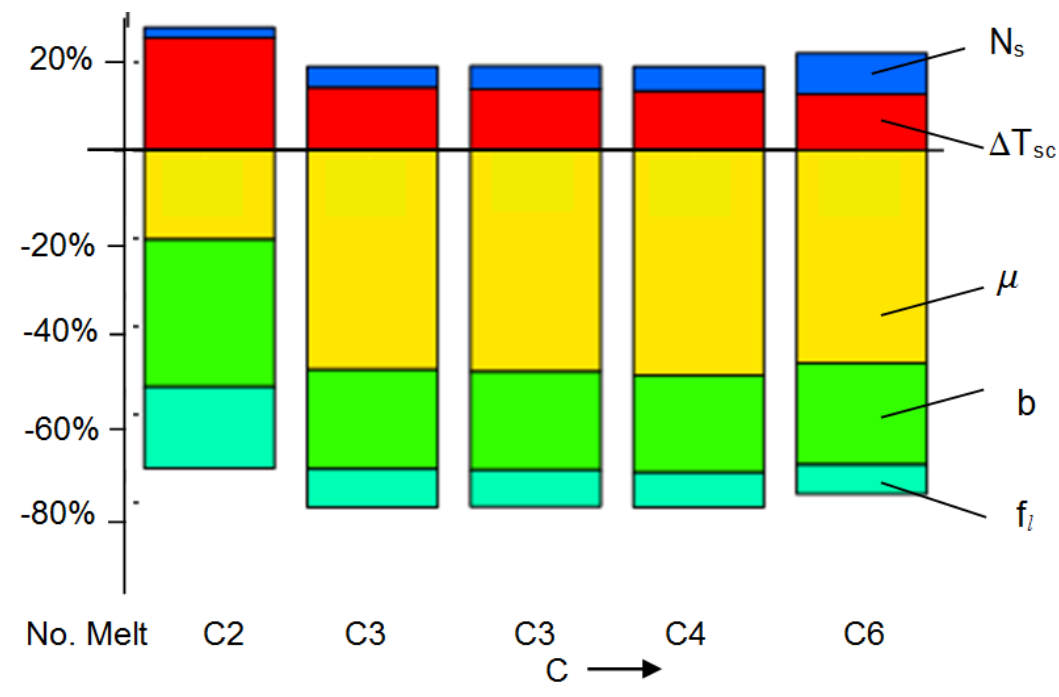

Figure 12. Carbon intensity effect on the $\mathrm{CT}$ index through $f l, \mu, \Delta T_{\mathrm{sc}}, N_{s}$ and $\mathrm{b}$ (- CT decreases; + CT increases).

\subsection{Effect of Silicon}

The results of the experimental measurements of $\mathrm{Si}$ in the cast iron and the initial liquid metal temperature just after pouring into the mold, $T_{\mathrm{i}}$, are given in Table 5, while the cooling rate, $Q$, of cast iron at the onset of solidification, the cell count and undercooling are shown in Figure 13. These results are reported in some detail elsewhere [31].

From Figure 13a, it is apparent that $\mathrm{Si}$ increases the cooling rate as a result of a reduction in the liquidus temperature, $T_{1}$. (just as with carbon). Si increases the number of eutectic cells in the experimental bars and wedges (Figure 13b), while reducing the undercooling (Figure 13c). The experimental results are described by the regression equations for $N_{F}, N_{\mathrm{F}, 1}, N_{\mathrm{cr}}, \Delta T_{\mathrm{m}}$ and $\Delta T_{\mathrm{m}, 1}$, and they are given in Table 5. Notice in particular that the experimental outcome is in good agreement with the predictions of Equations (5), (9) and (11) (see Figure 13).

Figure 14 shows the effect of silicon on the nucleation coefficients (Figure 14a,b), f (Figure 14c), $\Delta T_{\text {sc }}$ (Figure 14d) and $\mu$ (Figure 14e). Notice from these figures that in the range of up to $2.4 \% \mathrm{Si}$, there is an increase in the magnitude of $N_{s}$ and $b$. At approximately $2.4 \% \mathrm{Si}, N_{s}$ and $b$ reach a maximum, and then, they decrease. In contrast, $\mu$ deceases in the $\mathrm{Si}$ range of up to $2.4 \% \mathrm{Si}$, reaches a minimum and then increases. These correlations are described by the regression equations for $\mu, N_{s}$ and $b$ given in Table 5 . 
Table 5. Effect of silicon on the resultant $T_{i}$.

\begin{tabular}{|c|c|c|c|c|}
\hline \multirow{2}{*}{ No. Melt * } & \multirow{2}{*}{$\mathrm{Si}, \%$} & \multicolumn{3}{|c|}{ Initial Liquid Metal Temperature just after Pouring into the Mold, $T_{i},{ }^{\circ} \mathrm{C}$} \\
\hline & & Bar $2.8 \mathrm{~cm}$ & Bar $1.8 \mathrm{~cm}$ & Wedge \\
\hline Sil & 1.82 & 1,348 & 1,268 & 1,249 \\
\hline $\mathrm{Si} 2$ & 1.93 & 1,348 & 1,268 & 1,265 \\
\hline $\mathrm{Si3}$ & 2.04 & 1,348 & 1,268 & 1,261 \\
\hline $\mathrm{Si} 4$ & 2.11 & 1,348 & 1,268 & 1,241 \\
\hline $\mathrm{Si} 5$ & 2.22 & 1,374 & 1,251 & 1,247 \\
\hline Si6 & 2.53 & 1,351 & 1,253 & 1,252 \\
\hline Si7 & 2.70 & 1,352 & 1,235 & 1,239 \\
\hline $\mathrm{Si} 8$ & 2.85 & 1,354 & 1,279 & 1,276 \\
\hline \multicolumn{2}{|c|}{ Cell count, $\mathrm{cm}^{-2}$} & bar $2.8 \mathrm{~cm}$ & \multicolumn{2}{|c|}{$N_{F}=4,040.8-5,474.5 \mathrm{Si}+2,475.5 \mathrm{Si}^{2}-354.6 \mathrm{Si}^{3}$} \\
\hline \multicolumn{2}{|c|}{ Cell count, $\mathrm{cm}^{-2}$} & bar $1.8 \mathrm{~cm}$ & \multirow{2}{*}{\multicolumn{2}{|c|}{$\begin{array}{l}N_{\mathrm{F}, 1}=8,787.4-11,547 \mathrm{Si}+5,165.8 \mathrm{Si}-731.1 \mathrm{Si}^{3} \\
\mathrm{~N}_{\mathrm{cr}}=200,666.7-271,316.3 \mathrm{Si}+118,435.2 \mathrm{Si}^{2}- \\
16,272.5 \mathrm{Si}^{3}\end{array}$}} \\
\hline \multicolumn{3}{|c|}{ Critical cell count, $\mathrm{cm}^{-2}$} & & \\
\hline \multicolumn{2}{|c|}{ Undercooling, ${ }^{\circ} \mathrm{C}$} & bar $2.8 \mathrm{~cm}$ & $\Delta T_{\mathrm{m}}=51.2 \mathrm{Si}-11.6$ & \\
\hline \multicolumn{2}{|c|}{ Undercooling, ${ }^{\circ} \mathrm{C}$} & bar $1.8 \mathrm{~cm}$ & $\Delta T_{\mathrm{m}, 1}=49.4 \mathrm{Si}-11$ & \\
\hline \multicolumn{3}{|c|}{ wedge width of the chill, $\mathrm{cm}$} & $\mathrm{w}=2.5-1.45 \mathrm{Si}+0$ & \\
\hline \multicolumn{4}{|c|}{ Graphite eutectic growth coefficient } & \\
\hline \multicolumn{5}{|c|}{ Nucleation coefficients } \\
\hline \multirow{2}{*}{\multicolumn{3}{|c|}{$\begin{array}{l}{ }^{\circ} \mathrm{C} \\
\mathrm{cm}^{-3}\end{array}$}} & $b=822.5 \mathrm{Si}-170.9$ & \\
\hline & & & $N_{s}=7.7 \times 10^{7} \mathrm{Si}^{72.7} \mathrm{e}$ & \\
\hline
\end{tabular}

$* \mathrm{C}=3.20 \%-3.27 \% ; \mathrm{Mn}=0.072 \%-0.077 \% ; \mathrm{P}=0.018 \%-0.024 \% ; \mathrm{S}=0.010 \%-0.016 \%$.

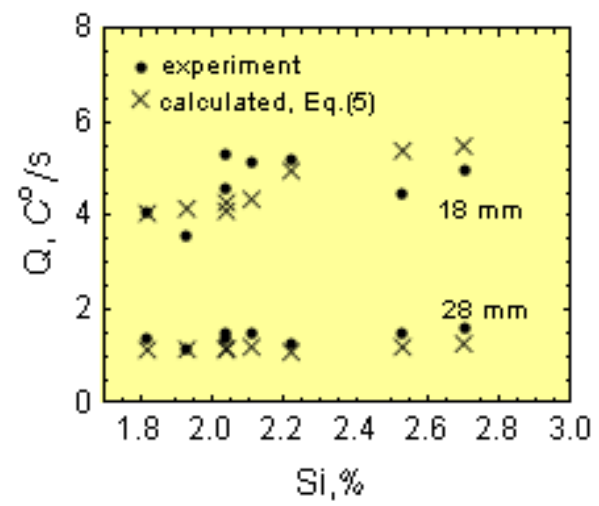

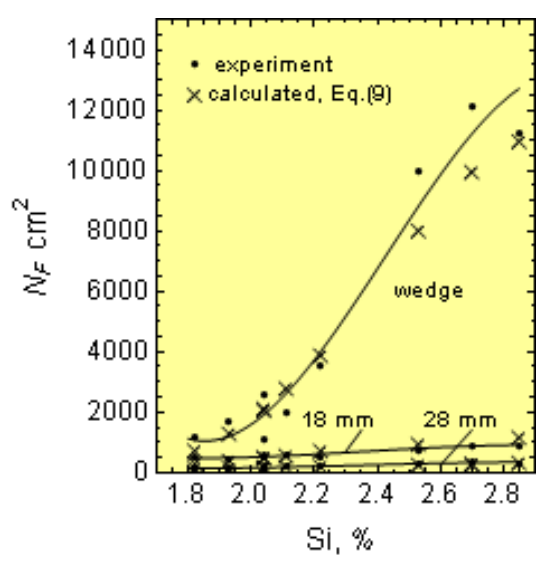

(b)

(a)

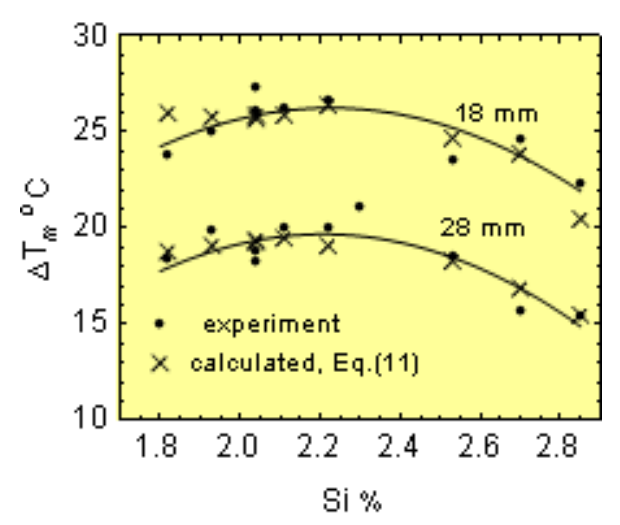

(c) 
Figure 13. Effect of $\mathrm{Si}$ on (a) $Q$, (b) $N_{F}$ and (c) $\Delta T_{\mathrm{m}}$.

Notice that the Si tendency to lower the magnitude of $\mu$ at low Si contents agrees with the data given in Table 3. Moreover, Si increases $\mathrm{f}$ and $\Delta T_{\mathrm{sc}}$. As a result, Si lowers the CT (Figure 14g) and increases $Q_{\text {cr }}$ (Figure 14f), diminishing the chill (Figure 14g). Notice that the experimental width of the chill and the one predicted using Equation (5) are rather similar (see Figure 14g).

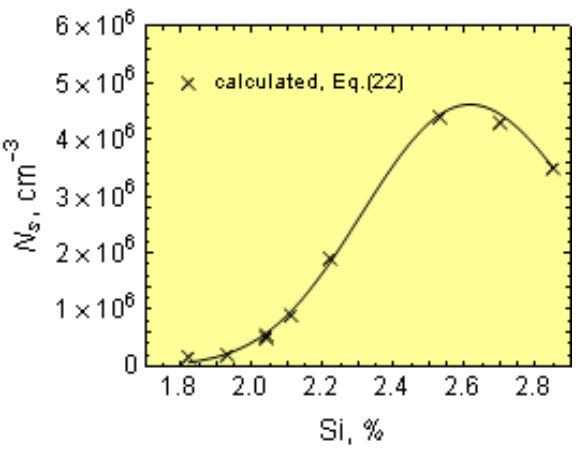

(a)

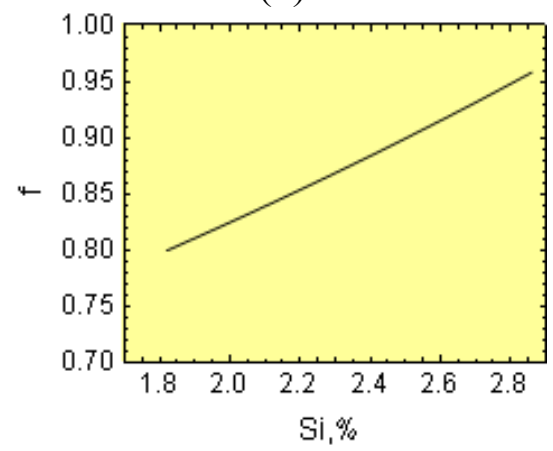

(c)

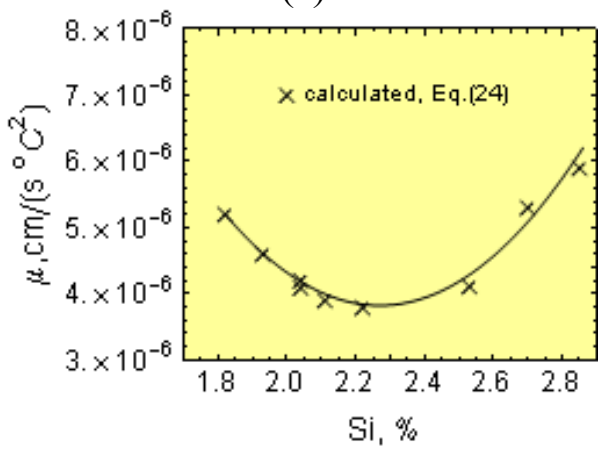

(e)

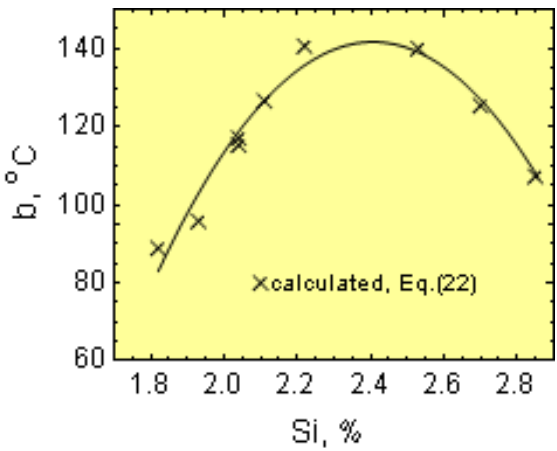

(b)

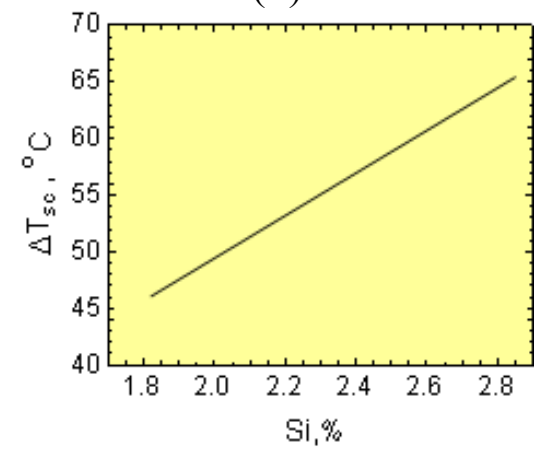

(d)

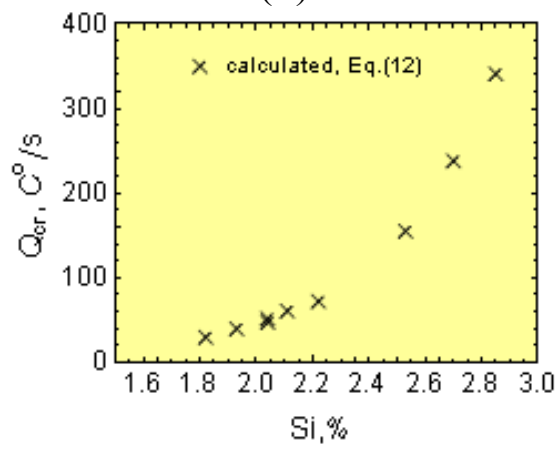

(f)

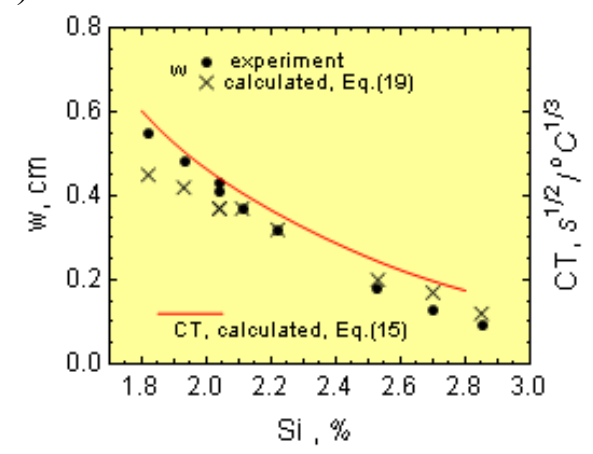

$(\mathbf{g})$

Figure 14. Effect of silicon on (a) $N_{s}$, (b) $b,(\mathbf{c}) f$, (d) $\Delta T_{\mathrm{sc}},(\mathbf{e}) \mu,(\mathbf{f}) Q_{\mathrm{cr}}$ and (g) the CT index and w. 
Similar to the effect of carbon, the influence of Si on the CT index through $\mathrm{f}, \mu, \Delta T_{\mathrm{sc}}, N_{s}$ and $b$ was determined (Figure 15).

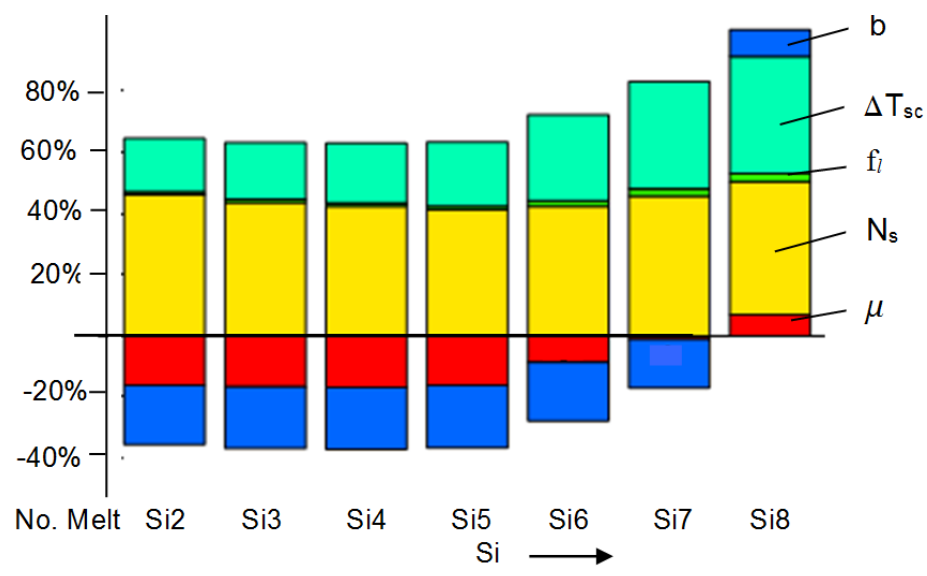

Figure 15. Silicon intensity effect on the CT index, through $f, \mu \Delta T_{\mathrm{sc}}, N_{s}$ and $b$ (- CT decreases; + CT increases).

From Figure 15, it is found that the intensity effect of the $\mathrm{Si}$ through $\mathrm{N}_{\mathrm{s}}$ and $\Delta T_{\mathrm{sc}}$ on the CT is strong. When the Si content increases, the intensity of the Si influence on CT through $\Delta T_{\mathrm{sc}}$ also increases, while it diminishes through $\mathrm{b}$ and $\mu$. The effect of Si on the CT through $\mathrm{f}$ is rather small.

\subsection{Effect of Manganese}

The experimental results on the effect of $\mathrm{Mn}$ on the various nucleation and growth factors in the cast iron are given in Table 6. In addition, Figure 16 shows the effect of $\mathrm{Mn}$ on $Q, N_{F}$ and $\Delta T_{\mathrm{m}}$.

Table 6. Effect of Mn on cast iron $T_{\mathrm{i}}$.

\begin{tabular}{|c|c|c|c|c|}
\hline \multirow[t]{2}{*}{ No. Melt * } & \multirow[t]{2}{*}{ Mn, \% } & \multicolumn{3}{|c|}{$\begin{array}{l}\text { Initial Liquid Metal Temperature just after Pouring into the Mold, } T_{i} \\
{ }^{\circ} \mathrm{C}\end{array}$} \\
\hline & & Bar $2.8 \mathrm{~cm}$ & Bar $1.8 \mathrm{~cm}$ & Wedge \\
\hline Mn1 & 0.078 & 1,350 & 1,248 & 1,242 \\
\hline $\mathrm{Mn} 2$ & 0.19 & 1,356 & 1,254 & 1,231 \\
\hline Mn3 & 0.33 & 1,360 & 1,260 & 1,256 \\
\hline $\mathrm{Mn} 4$ & 0.49 & 1,341 & 1,210 & 1,242 \\
\hline Mn5 & 0.73 & 1,348 & 1,264 & 1,244 \\
\hline Mn6 & 0.91 & 1,341 & 1,210 & 1,252 \\
\hline \multicolumn{2}{|c|}{ Cell count, $\mathrm{cm}^{-2}$} & bar $2.8 \mathrm{~cm}$ & \multicolumn{2}{|c|}{$N_{F}=115,587.8-119,801.3 \mathrm{Mn}+1.37 \times 10^{6} \mathrm{Mn}^{2}$} \\
\hline \multicolumn{2}{|c|}{ Cell count, $\mathrm{cm}^{-2}$} & bar $1.8 \mathrm{~cm}$ & \multicolumn{2}{|c|}{$N_{\mathrm{F}, 1}=322.3+457.5 \mathrm{Mn}$} \\
\hline \multicolumn{2}{|c|}{ Critical cell count, $\mathrm{cm}^{-2}$} & & \multicolumn{2}{|c|}{$N_{\mathrm{cr}}=569.5+367.9 \mathrm{Mn}$} \\
\hline \multicolumn{2}{|c|}{ Undercooling, ${ }^{\circ} \mathrm{C}$} & bar $2.8 \mathrm{~cm}$ & \multicolumn{2}{|c|}{$\Delta T_{\mathrm{m}}=18.7+5.4 \mathrm{Mn}$} \\
\hline \multicolumn{2}{|c|}{ Undercooling, ${ }^{\circ} \mathrm{C}$} & bar $1.8 \mathrm{~cm}$ & \multicolumn{2}{|c|}{$\Delta T_{\mathrm{m}, 1}=27.02+2.8 \mathrm{Mn}$} \\
\hline \multicolumn{2}{|c|}{ Wedge width of the chill, $\mathrm{cm}$} & & \multicolumn{2}{|c|}{$\mathrm{w}=0.92+0.22 \mathrm{Mn}$} \\
\hline $\begin{array}{l}\text { Graphite eut } \\
\mathrm{cm} /\left(\mathrm{s} \cdot{ }^{\circ} \mathrm{C}^{2}\right)\end{array}$ & \multicolumn{3}{|c|}{ Graphite eutectic growth coefficient, $\mu$} & $\mu_{\mathrm{s}}=10^{-6}(4.2-2.1 \mathrm{Mn})$ \\
\hline \multicolumn{5}{|c|}{ Nucleation coefficients } \\
\hline \multirow{2}{*}{\multicolumn{2}{|c|}{$\begin{array}{l}{ }^{\circ} \mathrm{C} \\
\mathrm{cm}^{-3}\end{array}$}} & & \multicolumn{2}{|c|}{$b=84.6+64.6 \mathrm{Mn}$} \\
\hline & & & \multicolumn{2}{|c|}{$N_{s}=115,587.8-119,801.3 \mathrm{Mn}+1.37 \times 10^{6} \mathrm{Mn}^{2}$} \\
\hline
\end{tabular}




$$
{ }^{*} \mathrm{C}=3.29 \%-3.37 \% ; \mathrm{Si}=1.21 \%-1.29 \% ; \mathrm{P}=0.020 \%-0.03 \% ; \mathrm{S}=0.01 \%-0.02 \% .
$$

Manganese increases the number of eutectic cells in bars and wedges (Figure 16b) and the undercooling (Figure 16c). These results are described by regression equations for $N_{F}, N_{\mathrm{F}, 1}, N_{\mathrm{cr}}, \Delta T_{\mathrm{m}}$ and $\Delta T_{\mathrm{m}, 1}$, and they are given in Table 6. Notice that the experimental and calculated values from Equations (5), (9) and (11) are very close to each other.

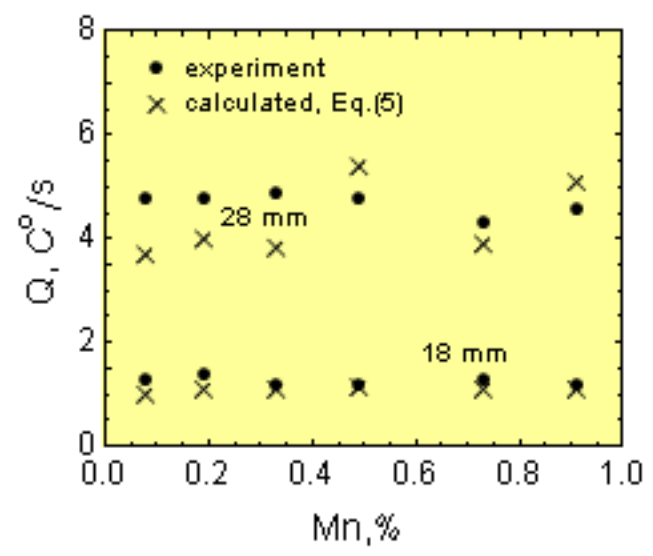

(a)

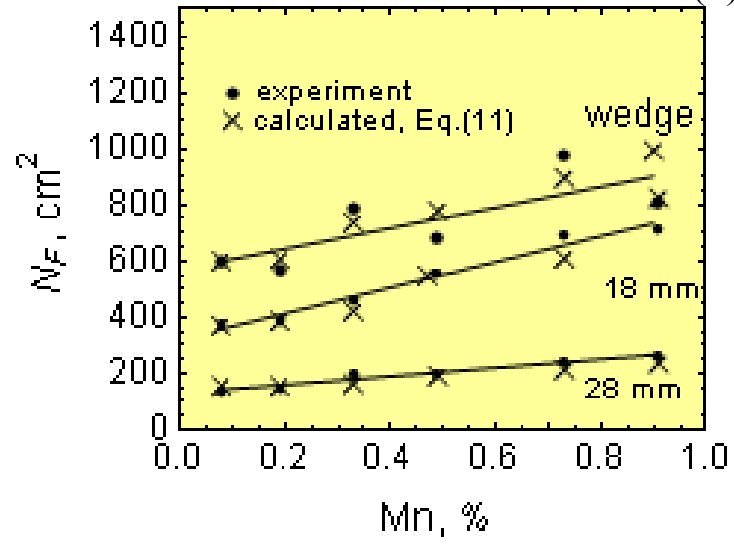

(b)

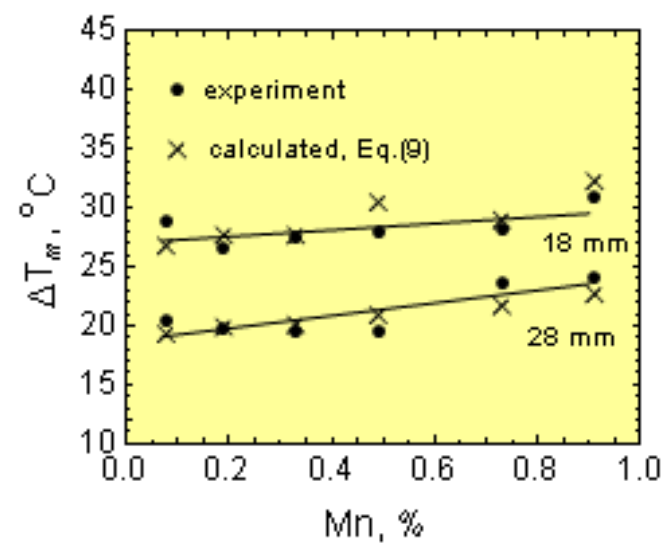

(c)

Figure 16. Effect of manganese on (a) $\mathrm{Q}$, (b) $\mathrm{N}_{\mathrm{F}}$ and (c) $\Delta T_{\mathrm{m}}$.

Manganese does not have a significant effect on $\mathrm{f}$ and $\Delta T_{\text {sc. }}$. Figure 17 shows the effect of $\mathrm{Mn}$ on the nucleation coefficients (Figure 17a,b) and on $\mu$ (Figure 17c) (see the regression equations for $\mu, N_{s}$ and $b$ given in Table 6). Notice from Figure 17 that $\mathrm{Mn}$ increases the nucleation coefficients, $\mathrm{N}_{\mathrm{s}}$ and $\mathrm{b}$, while decreasing $\mu$. In particular, the Mn tendency to lower $\mu$ agrees with the data given in Table 3 . $\mathrm{Mn}$ increases the CT index (Figure 17e) and $Q_{\mathrm{cr}}$ (Figure 17d), reducing the chill (Figure 17e). Notice that there is good agreement between the experimental outcome and the predictions of Equation (5) for w (see Figure 17e).

The manganese intensity effect on the CT index through $N_{s}, b$ and $\mu$ is shown in Figure 18. Notice that the most significant effect is on $N_{s}$. In addition, the intensity of the influence of Mn on the CT tendency index, through $\mu$ and $b$, is rather similar. 


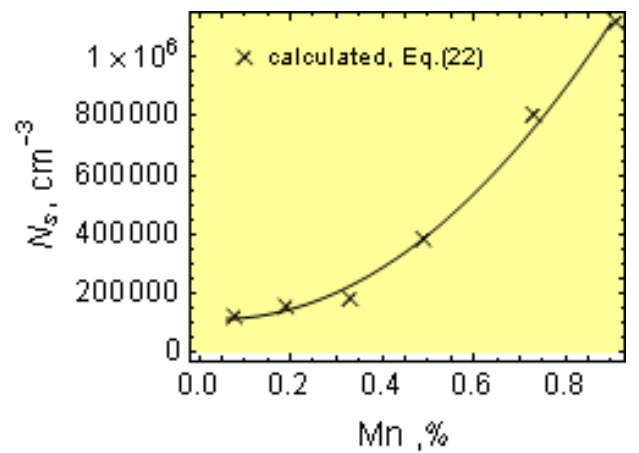

(a)

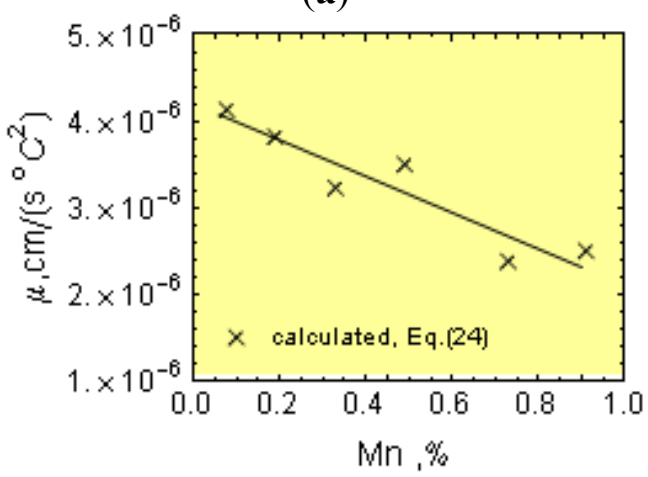

(c)

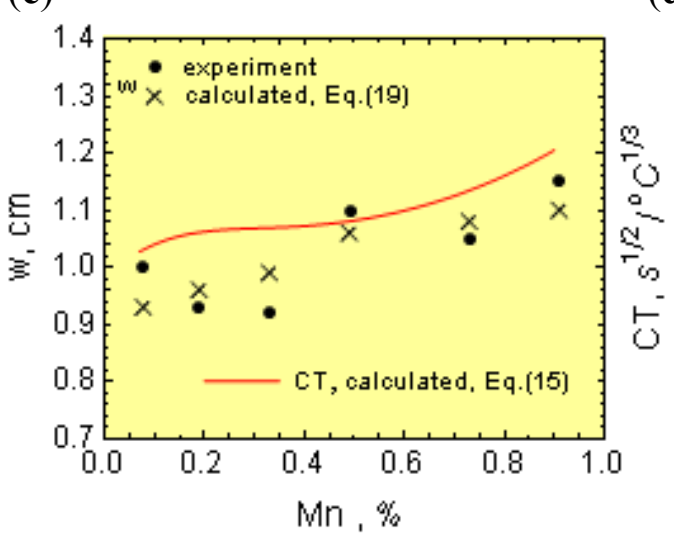

(e)

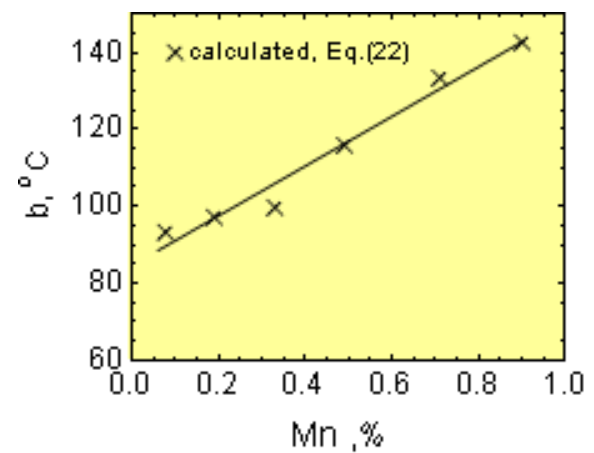

(b)

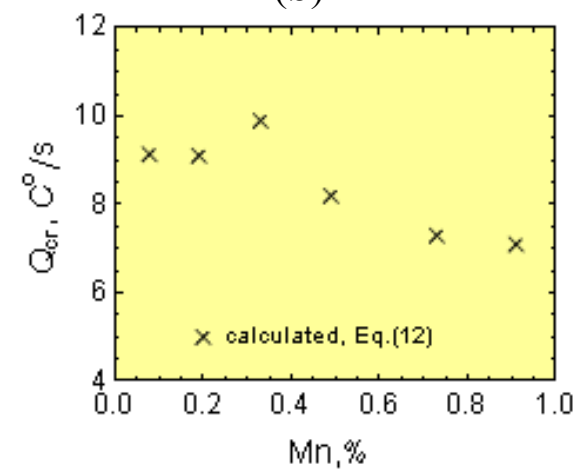

(d)

Figure 17. Effect of manganese on (a) $N_{s}$, (b) $b,(\mathbf{c}) \mu$, (d) CT index and (e) w.

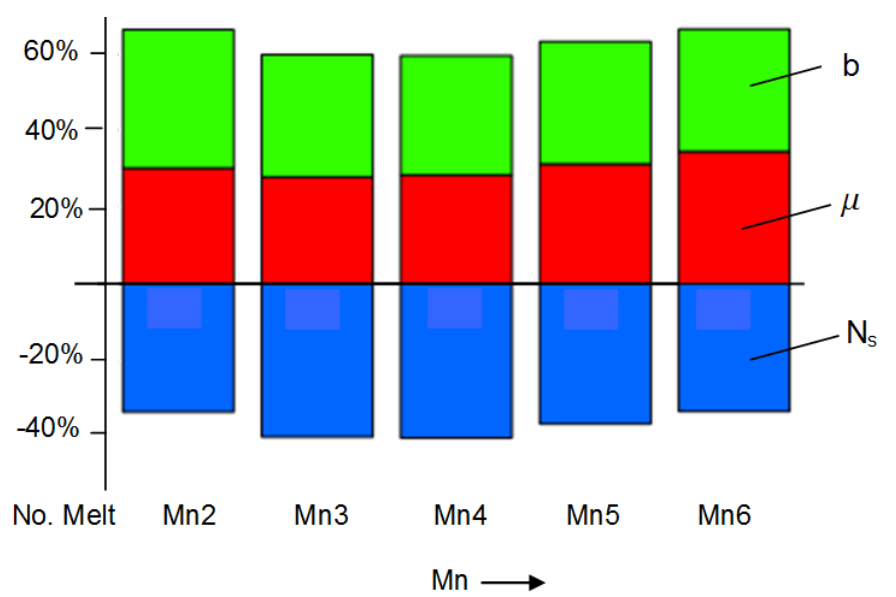

Figure 18. Manganese intensity effect on the CT index through $\mu, N_{s}$ and $b$ (- CT decreases; + CT increases). 


\subsection{Effect of Phosphorous}

The experimental results on the effect of $\mathrm{P}$ on the various nucleation and growth factors in the cast iron are given in Table 7. In addition, Figure 19 shows the effect of $\mathrm{P}$ on $\mathrm{Q}, N_{F}$ and $\Delta T_{\mathrm{m}}$.

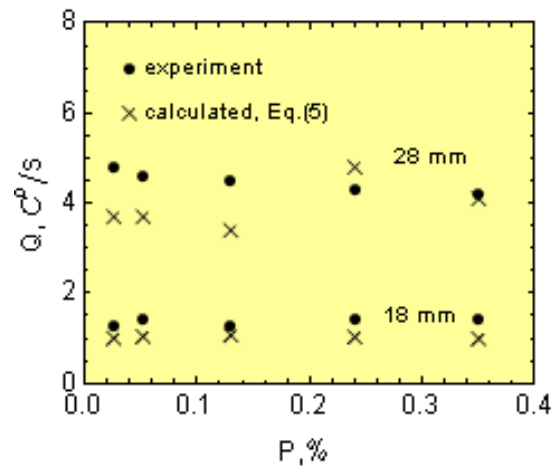

(a)

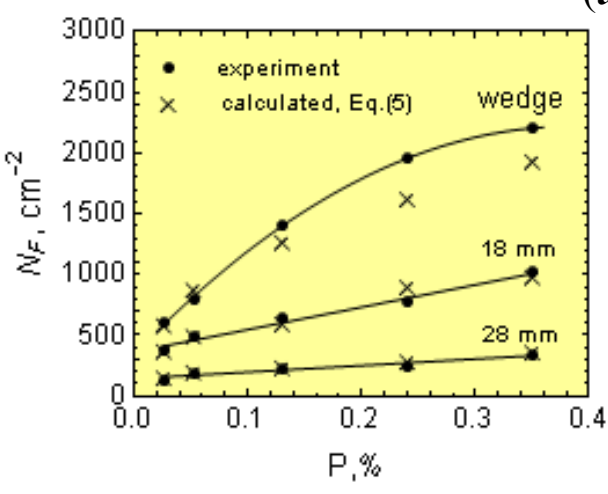

(b)

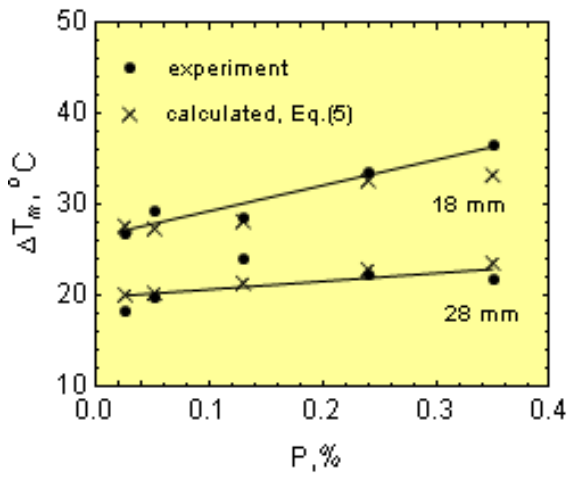

(c)

Figure 19. Effect of phosphorous on (a) $Q$, (b) $N_{F}$ and (c) $\Delta T_{\mathrm{m}}$.

Table 7. Effect of $\mathrm{P}$ on cast iron $T_{\mathrm{i}}$.

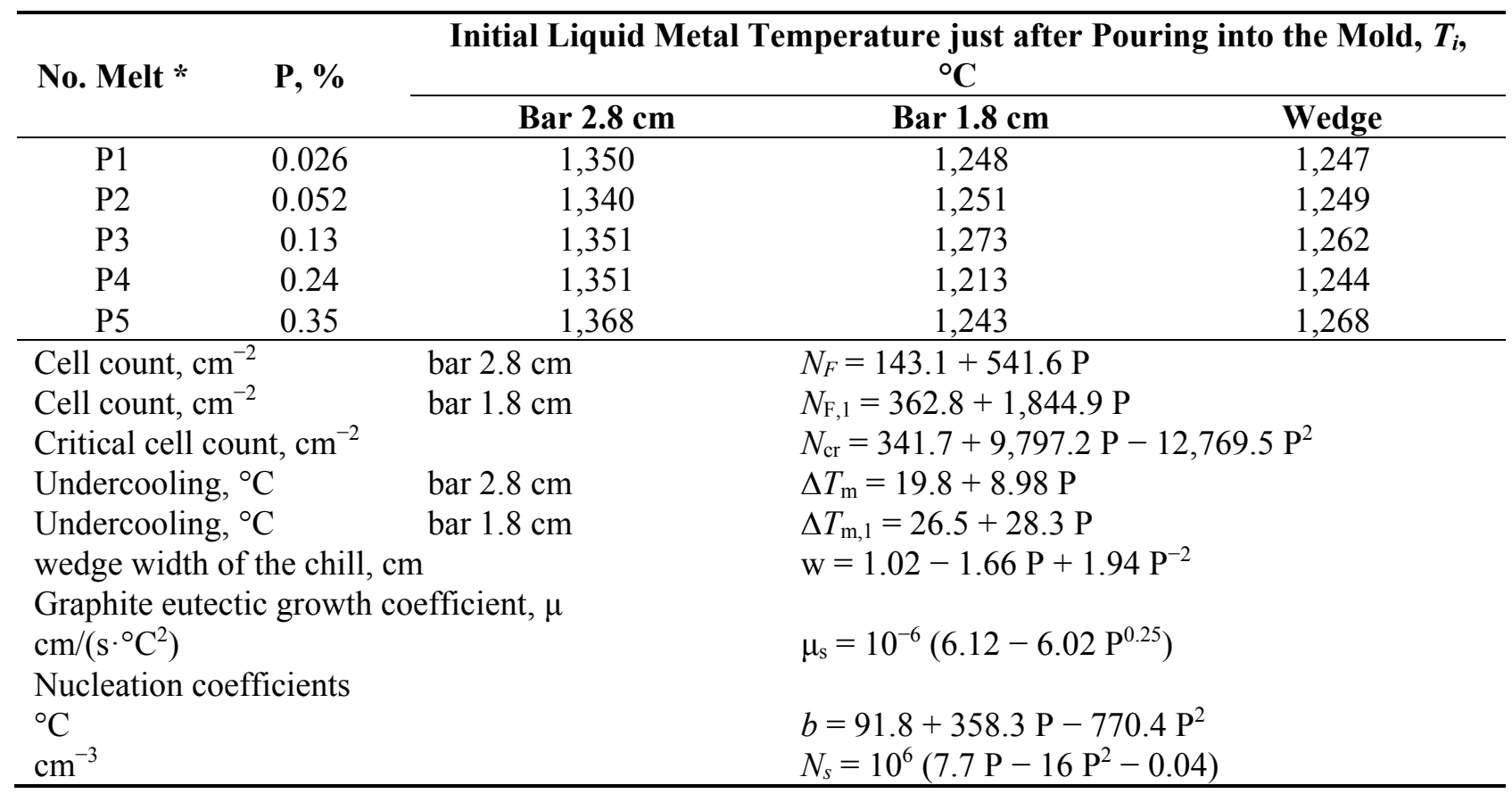

$* \mathrm{C}=3.29 \%-3.37 \% ; \mathrm{Si}=1.21 \%-1.29 \% ; \mathrm{P}=0.020 \%-0.03 \% ; \mathrm{S}=0.01 \%-0.02 \%$. 
Phosphorous increases the number of eutectic cells in in the experimental bars and wedges (Figure 19b) and the undercooling (Figure 19c). These results are described by regression equations for $N_{\mathrm{F}}, N_{\mathrm{F}, 1}, N_{\mathrm{cr}}, \Delta \mathrm{T}_{\mathrm{m}}$ and $\Delta T_{\mathrm{m}, 1}$, and they are given in Table 7 . Notice that the experimental and calculated values from Equations (5), (9) and (11) are rather similar.

Figure 20 shows the effect of $\mathrm{P}$ on the nucleation coefficients (Figure 20a,b) and on $\mu$ (Figure 20e) (see the regression equations for $\mu, N_{\mathrm{s}}$ and $b$ in Table 7). These correlations are described by regression equations for $\mu, N_{\mathrm{s}}$ and $b$ (Table 7). Notice from Figure 20a,b that for up to $0.25 \% \mathrm{P}$, phosphorous increases the nucleation coefficients, $\mathrm{N}_{\mathrm{s}}$ and $\mathrm{b}$, until they reach a maximum at approximately $\mathrm{P}=0.25 \%$. Furthermore, from Figure 20e, it is found that $\mathrm{P}$ lowers $\mu$ in agreement with the data given in Table 3 . In addition, $\mathrm{P}$ increases $\mathrm{f}$ (Figure 20c) and $\Delta T_{\text {sc }}$ (Figure 20d). P reduces the $\mathrm{CT}$ index (Figure 20g) and increases $Q_{\text {cr }}$ (Figure 20f), reducing the chill (Figure 20g). Notice that there is good agreement between the experimental outcome and the predictions of Equation (5) for w (see Figure 20g).

Notice from this figure that increasing the $\mathrm{P}$ content in the cast iron, the intensity influence of $\mathrm{P}$ on the CT index through $\mu$ and $\Delta T_{\text {sc }}$ increases, while decreasing through $N_{s}$ and $b$. The effect of the phosphorus through $\mathrm{f}$ on $\mathrm{CT}$ is negligible.

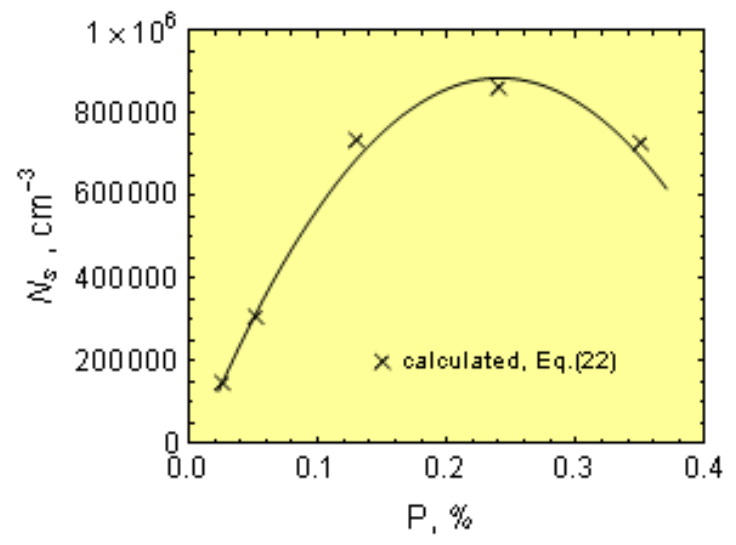

(a)

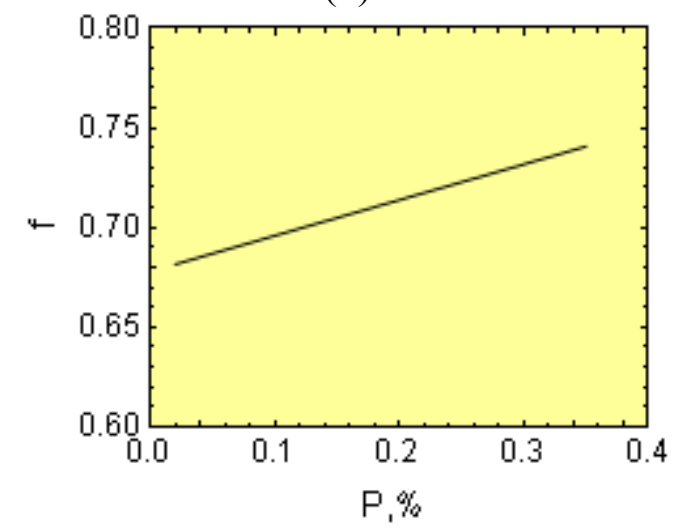

(c)

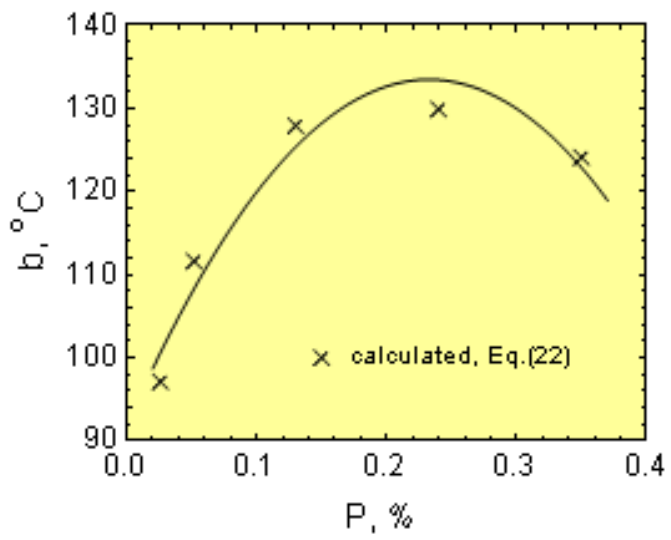

(b)

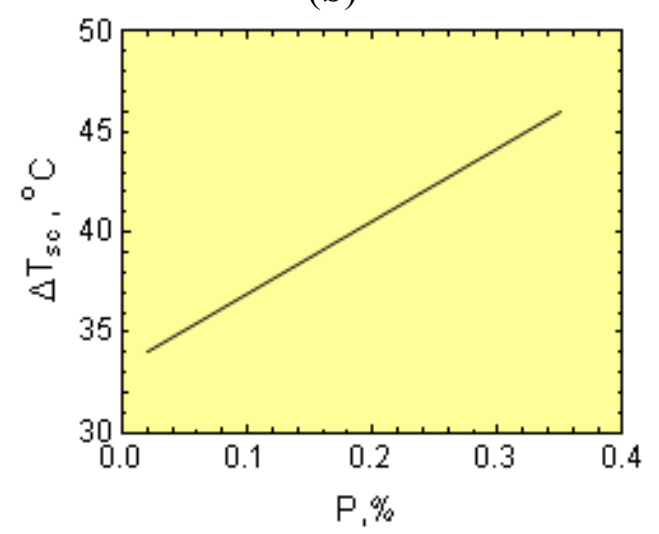

(d)

Figure 20. Cont. 


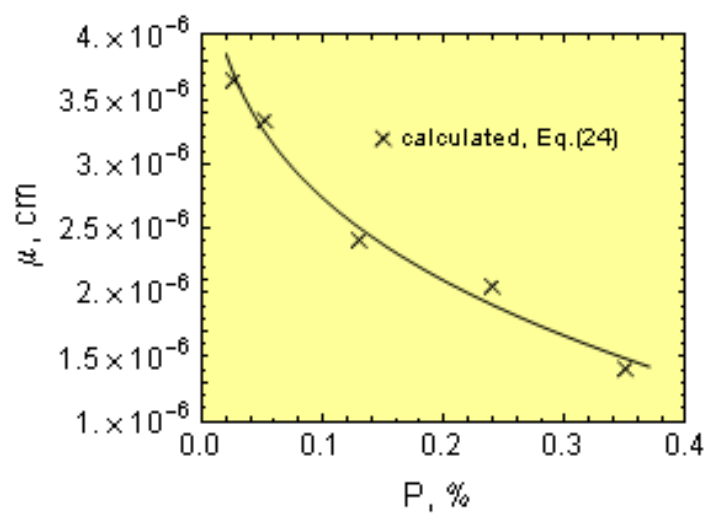

(e)

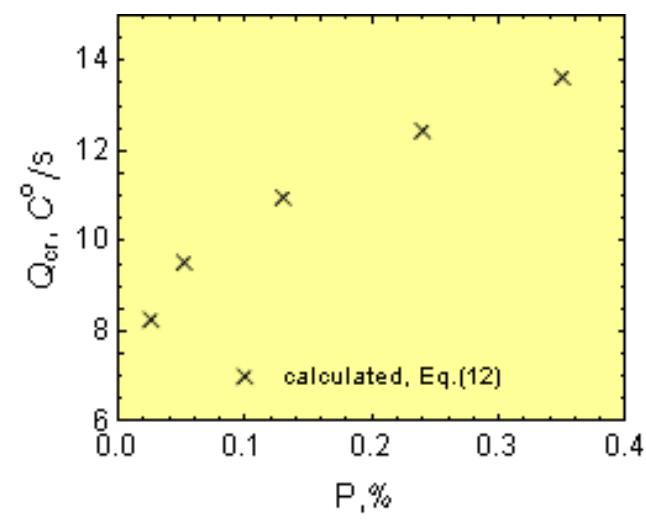

(f)

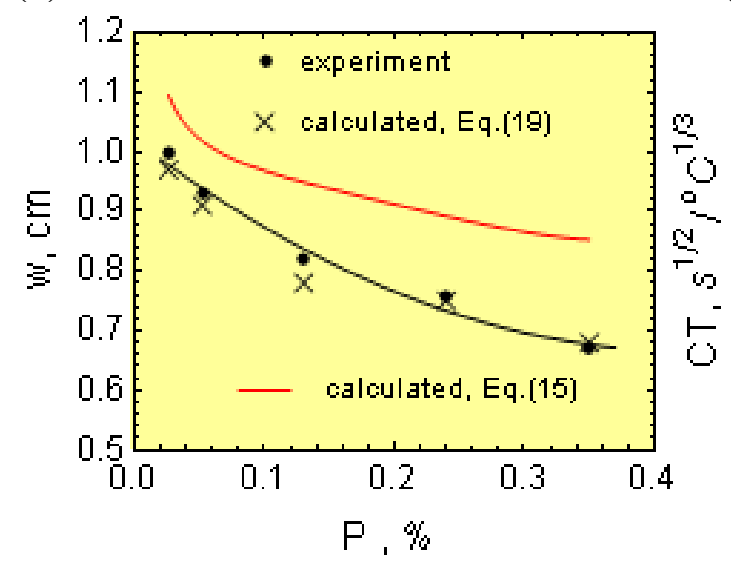

(g)

Figure 20. Effect of phosphorous on (a) $N_{\mathrm{s}},(\mathbf{b}) b,(\mathbf{c}) f,(\mathbf{d}) \Delta T_{\mathrm{sc}},(\mathbf{e}) \mu,(\mathbf{f}) Q_{\mathrm{cr}}$ and $(\mathbf{g}) \mathrm{w}$.

The phosphorous intensity effect on the CT index through f, $\mu \Delta T_{\mathrm{sc}}, N_{\mathrm{s}}$ and $b$ is shown in Figure 21.

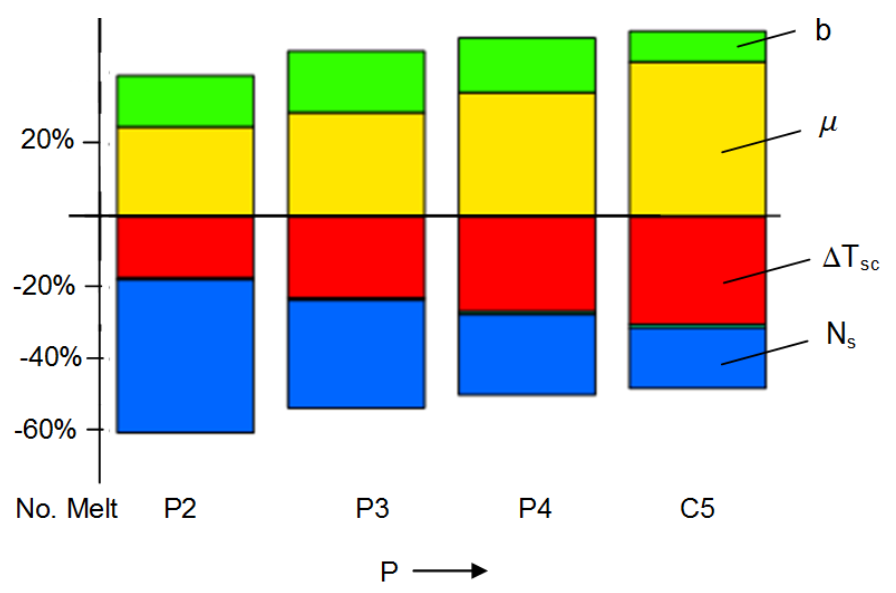

Figure 21. Phosphorous intensity effect on the CT index, through $\mu, N_{\mathrm{s}}, b, \Delta T_{\mathrm{sc}}$ and $f$ (- CT decreases; + CT increases).

\subsection{Effect of Sulfur}

The experimental results on the effect of $\mathrm{S}$ on the various nucleation and growth factors in the cast iron are given in Table 8. In addition, Figure 22 shows the effect of $\mathrm{S}$ on $Q, N_{F}$ and $\Delta T_{\mathrm{m}}$. These results are reported in some detail elsewhere [32,33]. 
Sulfur increases the number of eutectic cells in the experimental bars and wedges (Figure 22b) and the undercooling (Figure 22c). These results are described by regression equations for $N_{\mathrm{F}}, N_{\mathrm{F}, 1}, N_{\mathrm{cr}}$, $\Delta T_{\mathrm{m}}$ and $\Delta T_{\mathrm{m}, 1}$, and they are given in Table 8 . Notice that the experimental outcome and the calculated values from Equations (5), (9) and (11) are rather similar.

Table 8. Effect of $\mathrm{S}$ on the cast iron $T_{i}$.

\begin{tabular}{|c|c|c|c|c|}
\hline \multirow{2}{*}{ No. Melt * } & \multirow{2}{*}{$\mathrm{S}, \%$} & \multicolumn{3}{|c|}{ Initial Liquid Metal Temperature just after Pouring into the Mold, $T_{i},{ }^{\circ} \mathrm{C}$} \\
\hline & & Bar $2.8 \mathrm{~cm}$ & Bar $1.8 \mathrm{~cm}$ & Wedge \\
\hline S1 & 0.044 & 1,368 & 1,300 & 1,275 \\
\hline S2 & 0.079 & 1,354 & 1,245 & 1,247 \\
\hline S3 & 0.098 & 1,349 & 1,248 & 1,245 \\
\hline S4 & 0.121 & 1,355 & 1,251 & 1,242 \\
\hline S5 & 0.131 & 1,357 & 1,224 & 1,241 \\
\hline \multicolumn{2}{|c|}{ Cell count, $\mathrm{cm}^{-2}$} & bar $2.8 \mathrm{~cm}$ & $N_{\mathrm{F}}=9.4+4,267.2$ & \\
\hline \multicolumn{2}{|c|}{ Cell count, $\mathrm{cm}^{-2}$} & bar $1.8 \mathrm{~cm}$ & $N_{\mathrm{F}, 1}=231.1+11,5 \mathrm{C}$ & \\
\hline \multicolumn{2}{|c|}{ Critical cell count } & & $N_{\mathrm{cr}}=417.2+52,69$ & \\
\hline \multicolumn{2}{|c|}{ Undercooling, ${ }^{\circ} \mathrm{C}$} & bar $2.8 \mathrm{~cm}$ & $\Delta T_{\mathrm{m}}=15.2+55.8 \mathrm{~S}$ & \\
\hline \multicolumn{2}{|c|}{ Undercooling, ${ }^{\circ} \mathrm{C}$} & bar $1.8 \mathrm{~cm}$ & $\Delta T_{\mathrm{m}, 1}=19.2+96.1$ & \\
\hline \multicolumn{3}{|c|}{ wedge width of the chill, $\mathrm{cm}$} & $\mathrm{w}=0.2+1.8 \mathrm{~S}$ & \\
\hline \multicolumn{3}{|c|}{$\begin{array}{l}\text { Graphite eutectic growth coefficient, } \mu \\
\mathrm{cm} /\left(\mathrm{s}^{\circ} \mathrm{C}^{2}\right)\end{array}$} & $\mu_{\mathrm{s}}=10^{-6}(6.62-72$ & \\
\hline \multicolumn{3}{|c|}{ Nucleation coefficients } & & \\
\hline \multicolumn{3}{|c|}{$\begin{array}{l}{ }^{\circ} \mathrm{C} \\
\mathrm{cm}^{-3}\end{array}$} & $\begin{array}{l}b=78.8+470.5 \mathrm{~S} \\
N_{\mathrm{s}}=10^{6}(0.214843\end{array}$ & $\left.206 S^{2}\right)$ \\
\hline
\end{tabular}

* $\mathrm{C}=3.29 \%-3.35 \% ; \mathrm{Si}=2.21 \%-2.27 \% ; \mathrm{Mn}=0.077 \%-0.082 \% ; \mathrm{P}=0.020 \%-0.03 \%$.

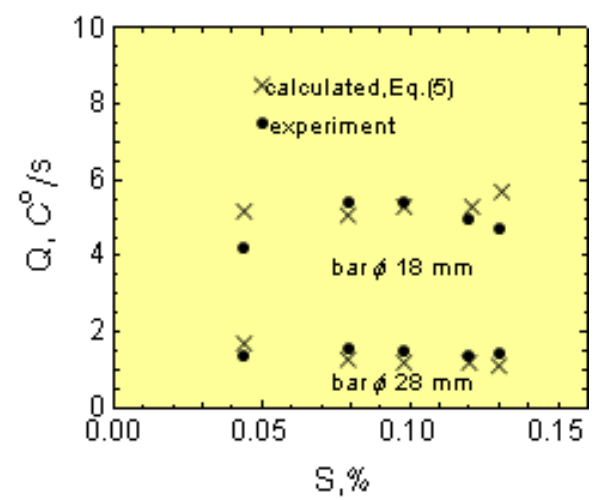

(a)

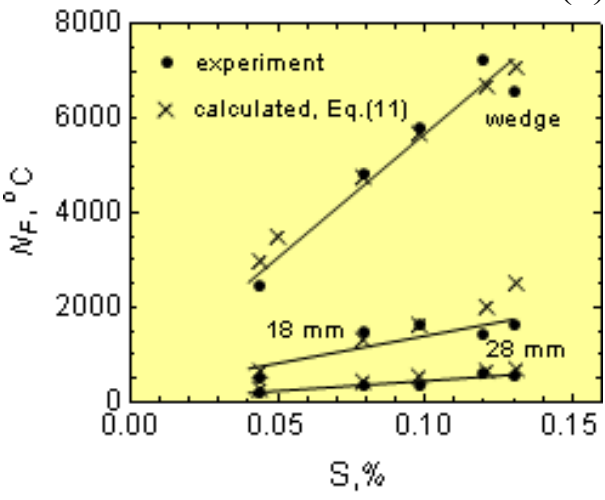

(b)

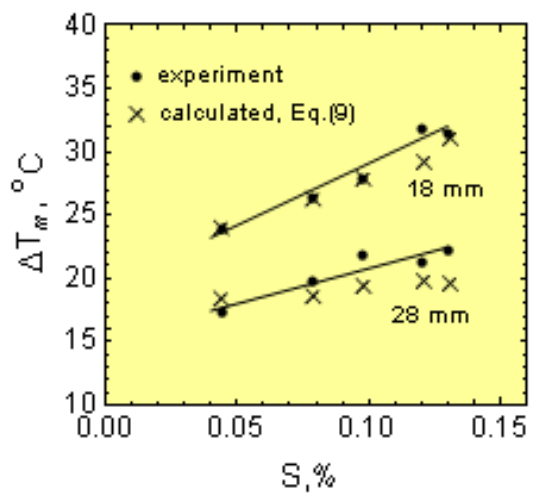

(c)

Figure 22. Effect of sulfur on (a) $Q$, (b) $N_{\mathrm{F}}$ and (c) $\Delta T_{\mathrm{m}}$. 
Sulfur does not have a significant effect on $\mathrm{f}$ nor on $\Delta T_{\mathrm{sc}}$. Figure 23 shows the $\mathrm{S}$ effect on $N_{\mathrm{s},} b$ (Figure 23a,b) and $\mu$ (Figure 23c). These correlations are described by regression equations for $\mu, N_{\mathrm{s}}$ and $\mathrm{b}$ in Table 8. Notice from Figure 23 that $\mathrm{S}$ increases $\mathrm{N}_{\mathrm{s}}$ and $\mathrm{b}$, while lowering $\mu$. The $\mathrm{S}$ tendency to lower $\mu$ is in agreement with the data given in Table 3. Sulfur increases the CT index (Figure 23e) and lowers $Q_{\text {cr }}$ (Figure 23d), thus diminishing the chill (Figure 23e). Notice that there is good agreement between the experimental and the predictions of Equation (5) for w (see Figure 23e).

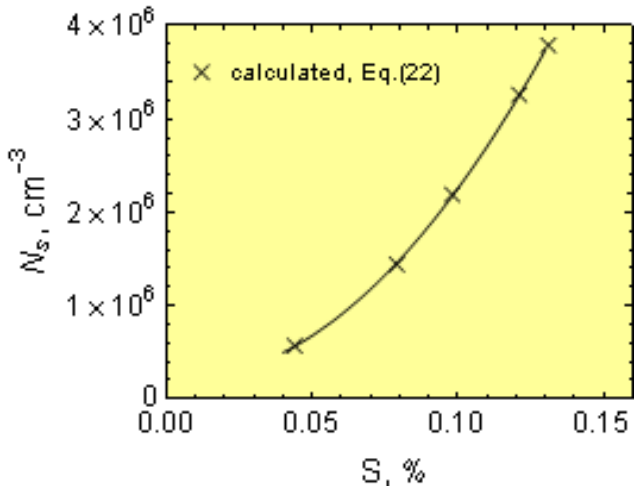

(a)

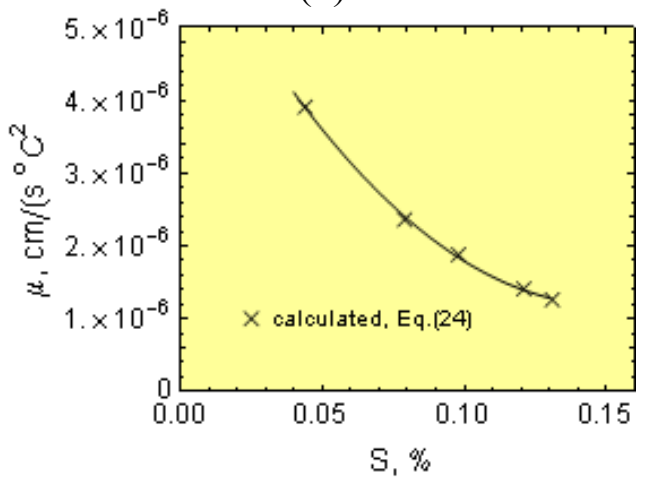

(c)

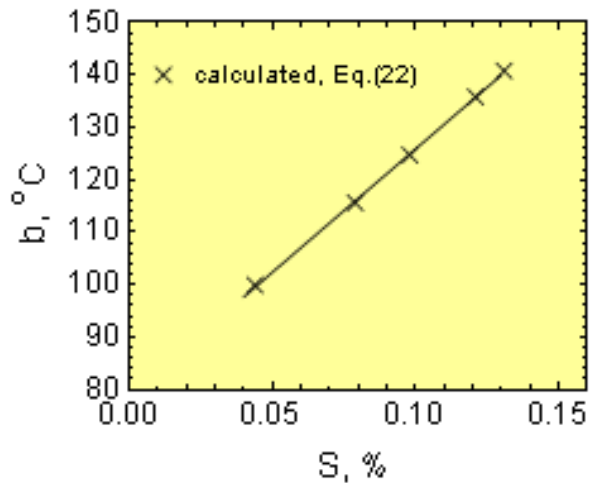

(b)

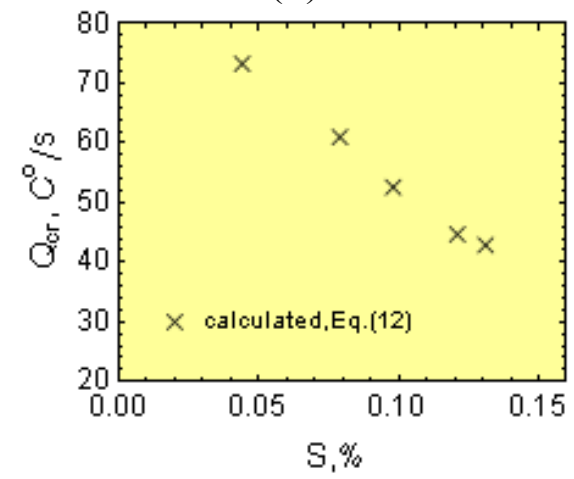

(d)

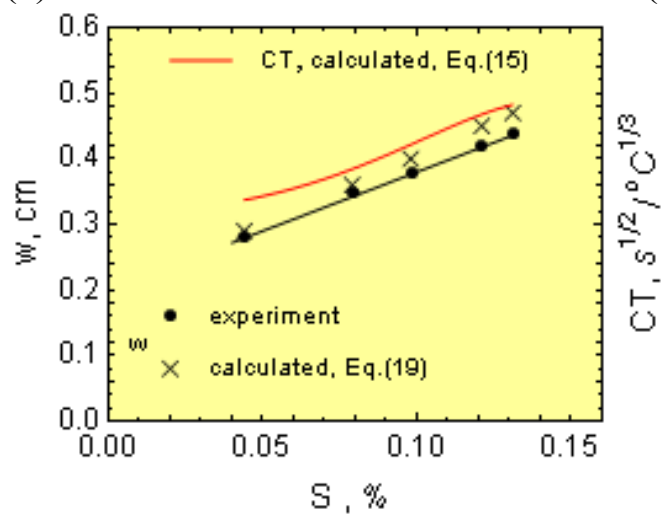

(e)

Figure 23. Effect of sulfur on (a) $N_{s}$, (b) $b,(\mathbf{c}) \mu$, (d) CT index and (e) w.

Figure 24 shows the intensity effect of $\mathrm{S}$ on the CT index through $\mu, N_{\mathrm{s}}$ and $b$. Notice that the most significant effect of $\mathrm{S}$ is through $\mu$. When the $\mathrm{S}$ content in the cast iron increases, the intensity influence of $\mathrm{S}$ on the CT index increases through $\mu$, while it is reduced through $N_{\mathrm{s}}$ and $b$. 


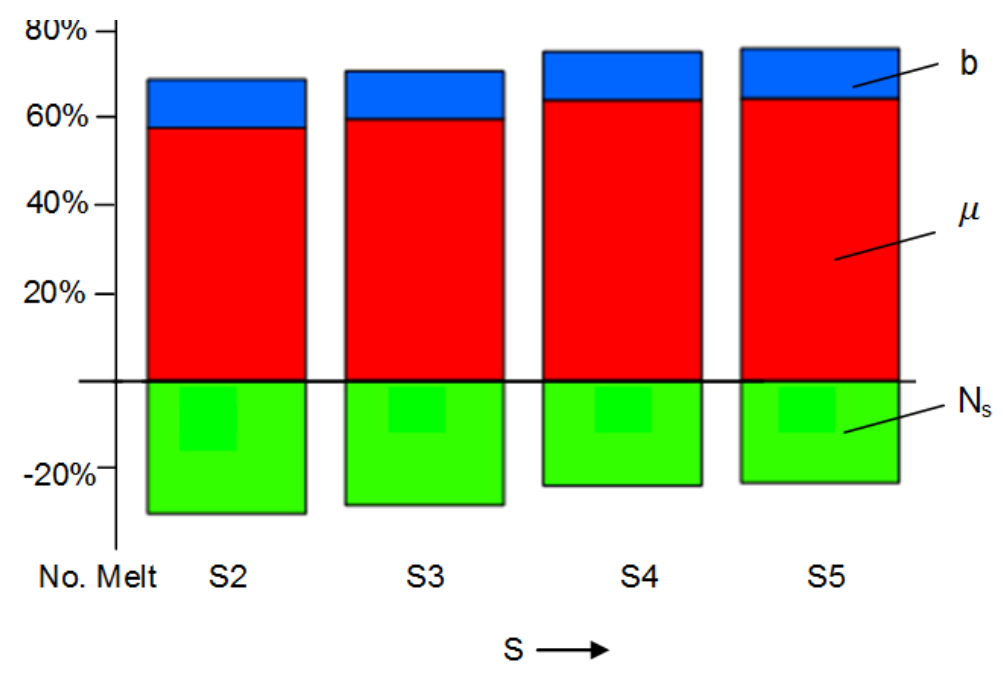

Figure 24. Sulfur intensity effect on the CT index through $\mu, \mathrm{N}_{\mathrm{s}}$ and $\mathrm{b}(-\mathrm{CT}$ decreases; $+\mathrm{CT}$ increases).

\subsection{Inoculation}

In a previously published work [27], experimental data on fading effects in cast iron had been reported using plate- and wedge-shaped castings of various sizes. The reported experimental work included inoculated and non-inoculated cast irons and the time-temperature history of the inoculation effects (fading). The results are given as a dimensionless function of time calculated from the instant when the inoculant was introduced in the melt as:

$$
t_{r}=\frac{t_{a}}{t}
$$

where $t_{\mathrm{a}}$ is given in Table 9 and $t$ is a reference time during which changes in the cell count are negligible (approximately $25 \mathrm{~min}$ ).

Table 9. Absolute and relative times after inoculation in cast iron and their effects on $N_{F}$.

\begin{tabular}{|c|c|c|c|c|c|c|c|c|}
\hline \multirow{2}{*}{\multicolumn{2}{|c|}{ No. Melt }} & 1 & 2 & 3 & 4 & 5 & 6 & 7 \\
\hline & & Base Iron & \multicolumn{6}{|c|}{ Inoculated Iron } \\
\hline \multicolumn{2}{|c|}{ Absolute time after inoculation, $t_{\mathrm{a}}$, min } & - & 1.5 & 5 & 10 & 15 & 20 & 25 \\
\hline \multicolumn{2}{|c|}{ Relative time after inoculation, $t_{\mathrm{r}}$} & - & 0.06 & 0.2 & 0.4 & 0.6 & 0.8 & 1.0 \\
\hline Cell count, $\mathrm{cm}^{-2}$ & plate $1.0 \mathrm{~cm}$ & \multicolumn{7}{|c|}{$N_{\mathrm{F}, 1}=2,619.0-4,302.2 t_{\mathrm{r}}+2,108.4 t_{\mathrm{r}}^{2}$} \\
\hline Cell count, $\mathrm{cm}^{-2}$ & plate $2.2 \mathrm{~cm}$ & \multicolumn{7}{|c|}{$N_{\mathrm{F}}=358.8-414.6 t_{\mathrm{r}}+128.3 t_{\mathrm{r}}^{2}$} \\
\hline Undercooling, ${ }^{\circ} \mathrm{C}$ & plate $1.0 \mathrm{~cm}$ & \multicolumn{7}{|c|}{$\Delta T_{\mathrm{m}, 1}=22.4+3.0 t_{\mathrm{r}}+7.3 t_{\mathrm{r}}^{2}$} \\
\hline Undercooling, ${ }^{\circ} \mathrm{C}$ & plate $2.2 \mathrm{~cm}$ & \multicolumn{7}{|c|}{$\Delta T_{\mathrm{m}}=16.2-0.06 t_{\mathrm{r}}+8.8 t_{\mathrm{r}}^{2}$} \\
\hline \multicolumn{9}{|c|}{ Wedge width of the chill, $\mathrm{cm}$} \\
\hline base cast iron & & \multicolumn{7}{|l|}{$\mathrm{w}=0.8$} \\
\hline inoculated cast iron & & \multicolumn{7}{|c|}{$\mathrm{W}=0.32+0.17 t_{\mathrm{r}}+0.05 t_{\mathrm{r}}^{2}$} \\
\hline \multicolumn{9}{|c|}{ Graphite eutectic growth coefficient, $\mathrm{cm} /\left(\mathrm{s} \cdot{ }^{\circ} \mathrm{C}^{2}\right)$} \\
\hline base cast iron & & \multicolumn{7}{|c|}{$\mu=2.64 \times 10^{-6}$} \\
\hline inoculated cast iron & & \multicolumn{7}{|c|}{$\mu=1.79 \times 10^{-6}$} \\
\hline
\end{tabular}


Table 9. Cont.

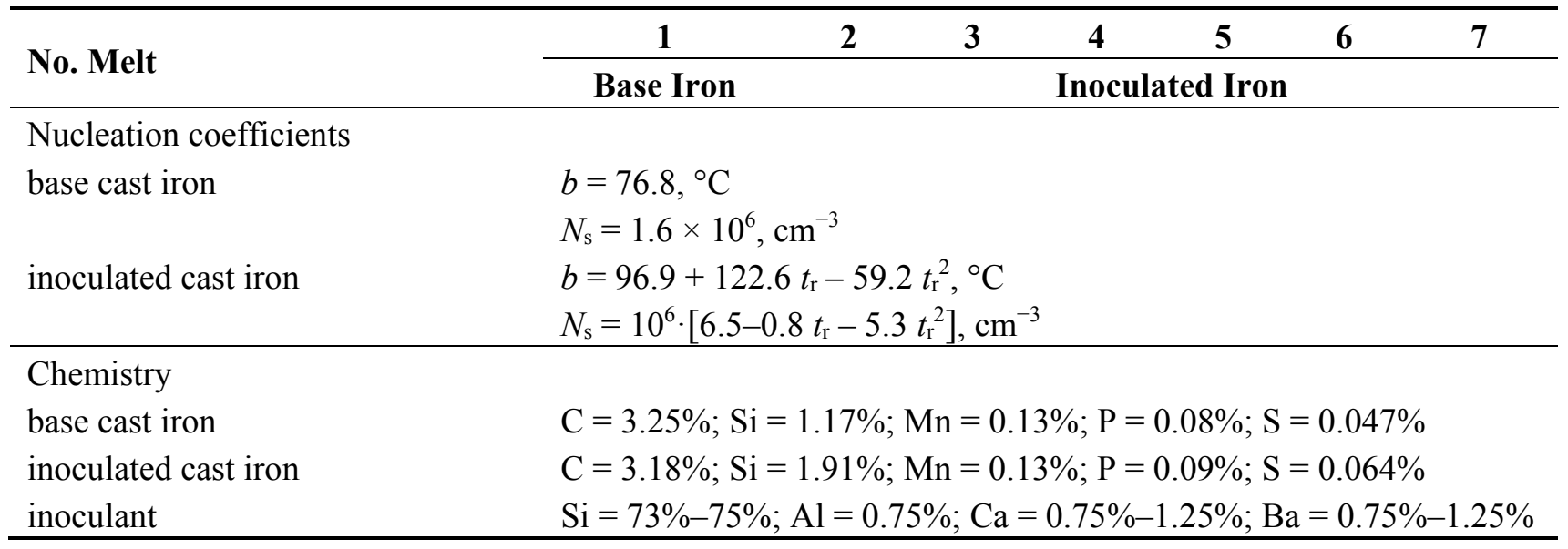

Figure 25 shows that the cell count (Figure 25a) diminishes while the undercooling increases (Figure 25b) with $t_{\mathrm{r}}$. In addition, Figure 25c,d shows the effect of $t_{\mathrm{r}}$ after inoculation on the nucleation coefficients. Notice from these figures that $N_{\mathrm{s}}$ increases, while b decreases with $t_{\mathrm{r}}$. As a result, the CT index increases (Figure 25f), and the $Q_{\text {cr }}$ is reduced (Figure 25e), lowering the chill (Figure 25f).

Figure 26 shows the $t_{\mathrm{r}}$ intensity effect on the CT index through $N_{s}$ and $b$. Notice that $t_{\mathrm{r}}$ does not have an effect on $\mathrm{f}, \Delta T_{\mathrm{sc}}$ and $\mu$ (i.e., the chemistry of the cast iron is a constant). Apparently, the $\mathrm{CT}$ index is affected by the nucleation parameters $\mathrm{Ns}$ and $\mathrm{b}$ with $t_{\mathrm{r}}$ (increasing through $N_{s}$ and decreasing through b).

From the graphite nucleation potential curves, the following arguments can be made for the nucleation of graphite cells. Consider two melts (base and inoculated irons). For the base melt, the nucleation potential is given by the curve $\mathrm{n}(l)$, which is relatively small when compared with that for inoculated iron, $\mathrm{n}_{i}(l)$ (Figure $9 \mathrm{~b}$ ). Although, $\Delta T_{\mathrm{m}}$ for the base melt is higher than for the inoculated melt, $\Delta T_{\mathrm{mi}}$, the area below the curve $\mathrm{n}(l)$ for $l_{\mathrm{m}} \leq l \leq \infty\left(0 \leq \Delta T \leq \Delta T_{\mathrm{m}}\right)$ is smaller than the area below the curve $\mathrm{n}_{\mathrm{i}}(l)$ in the range $l_{\mathrm{m}, \mathrm{i}} \leq l \leq \infty\left(0 \leq \Delta T \leq \Delta T_{\mathrm{m}, \mathrm{i}}\right)$. In turn, this indicates that during solidification, the inoculated melt contains a higher nuclei density than the base melt.

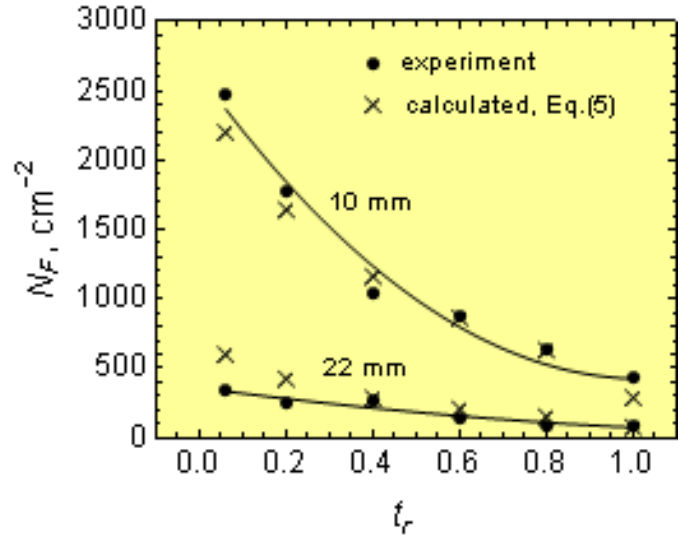

(a)

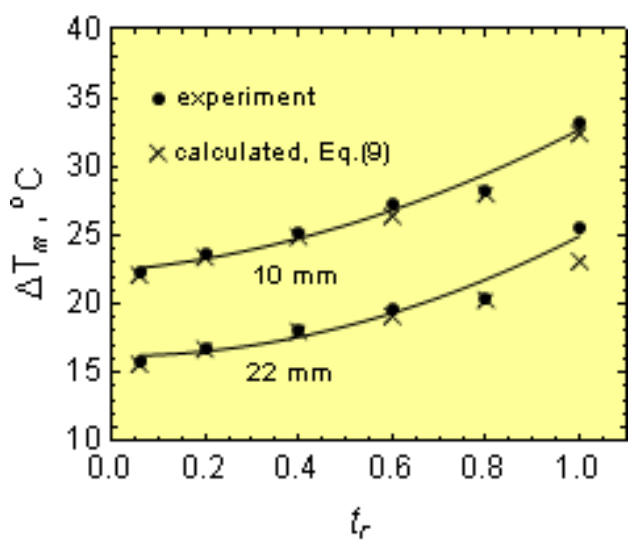

(b)

Figure 25. Cont. 


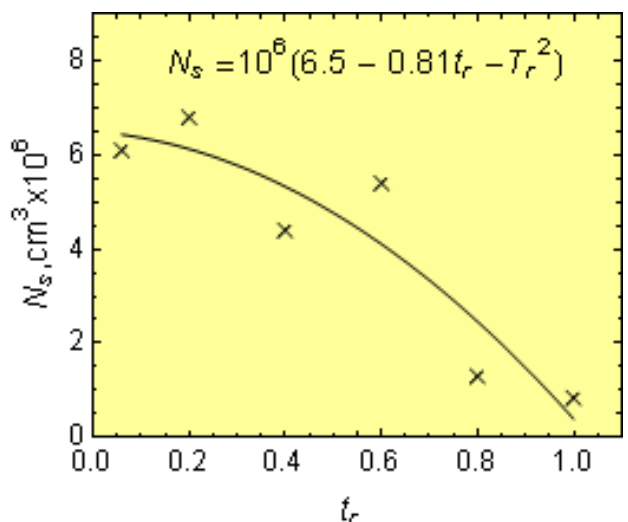

(c)

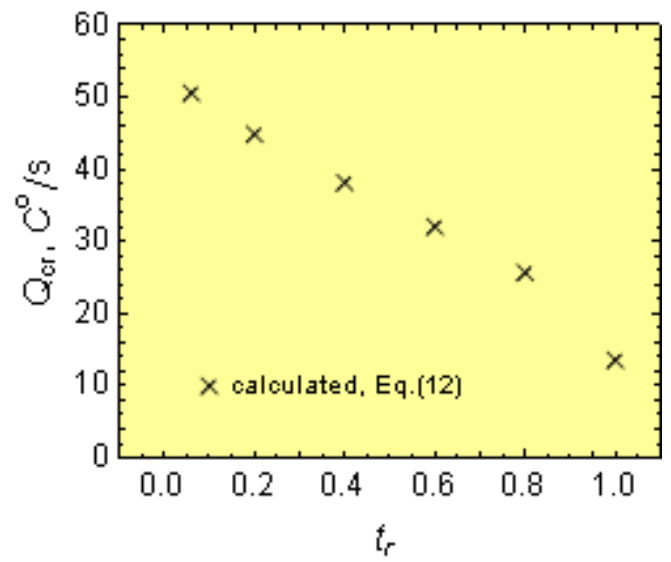

(e)

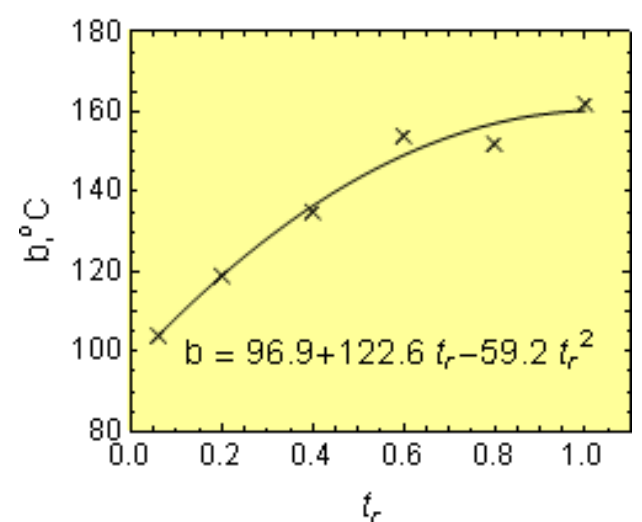

(d)

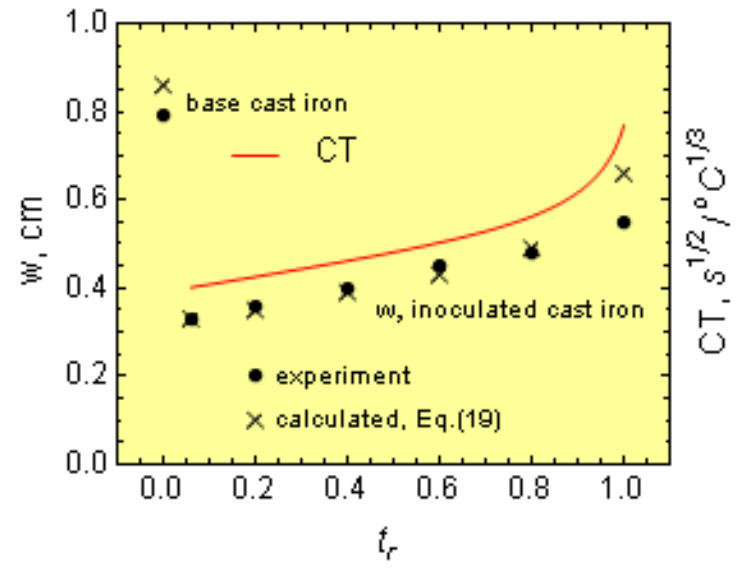

(f)

Figure 25. Effect of $t_{\mathrm{r}}$ after inoculation on (a) $N_{F}$, (b) $\Delta T_{\mathrm{m}}$, (c) $N_{s}$, (d) $b$, (e) the CT index and (f) w.

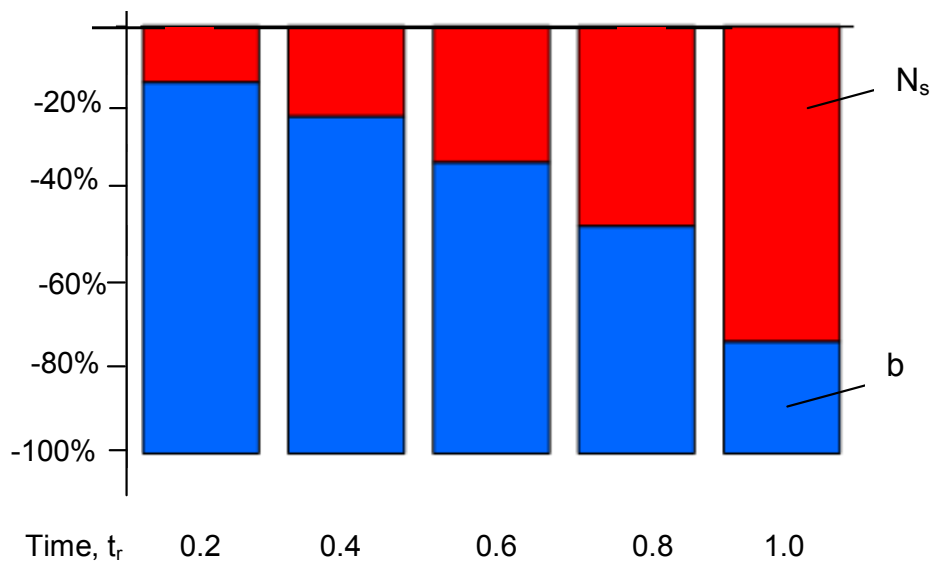

Fading of inoculation $\longrightarrow$

Figure 26. Intensity effect of $t_{\mathrm{r}}$ on the CT index through $N_{s}$ and $\mathrm{b}(-\mathrm{CT}$ decreases).

Finally, in the present work, the role of various technological parameters on the CT index and the chill of cast iron can be explained by means of a common analytical model of general validity. This theory was experimentally verified using $\mathrm{C}, \mathrm{Si}, \mathrm{Mn}, \mathrm{P}$ and $\mathrm{S}$, and it includes fading effects as examples. Consequently, general relations can be found between $Q_{\mathrm{cr}}$, the CT index and the chill (see Figure 27). 


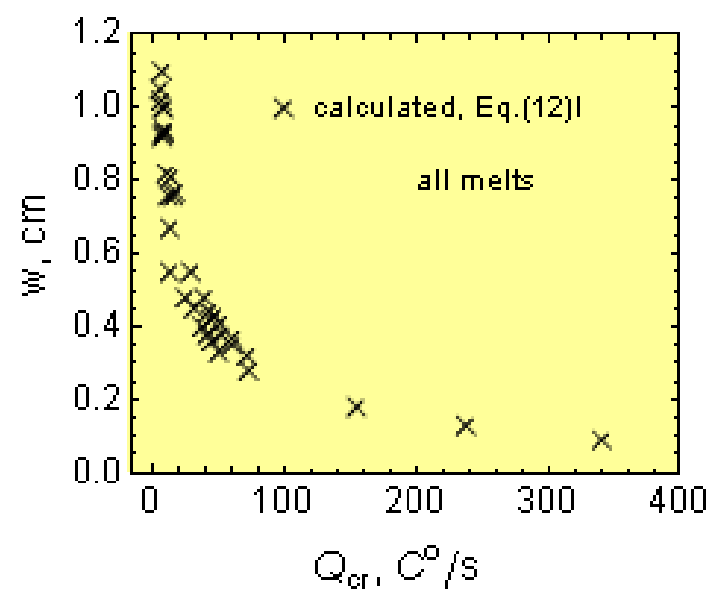

(a)

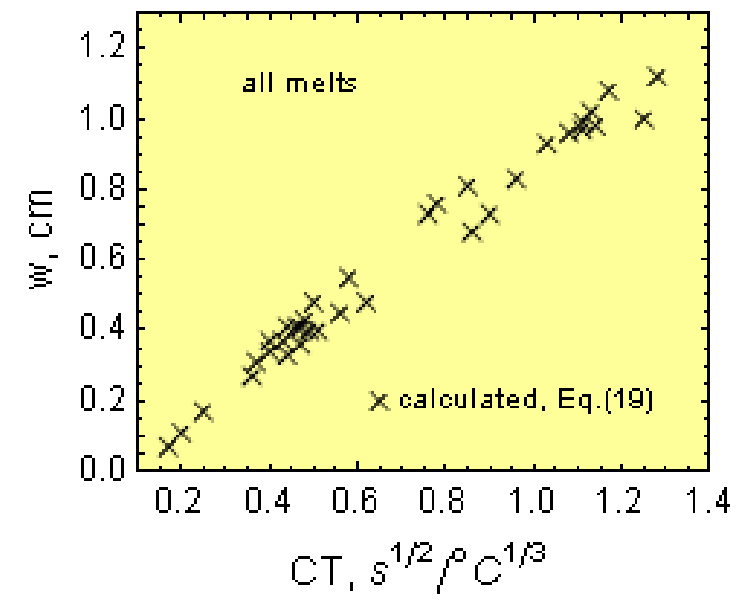

(b)

Figure 27. Relationship between (a) $Q_{\text {cr }}$ and the chill, w, and (b) the CT and w for all melts. Experimental and calculated values were found using Equation (19).

\section{Conclusions}

In this work, experimental and theoretical results on cast iron solidification and chill tendencies, $\mathrm{CT}$, are found to be in good agreement with each other, and they are summarized as follows:

- Carbon decreases $N_{s}, b$ and $\Delta T_{\mathrm{sc}}$ and increases $\mu, f$ and $Q_{\mathrm{cr}}$; as a result, $\Delta T_{\mathrm{m}}$ decreases, $Q_{\mathrm{cr}}$ and $N_{F}$ increase, while the CT and the w decrease.

- Silicon increases f and $\Delta T_{\mathrm{sc}}$ for the entire range of silicon content; it also increases $N_{s}$ and $\mathrm{b}$ for up to $2.4 \%$ Si followed by a reduction in its effect. Furthermore, Si lowers $\mu$ in the range of $0-2.4 \% \mathrm{Si}$, and this is followed by an increase in $\mu$. As a result, $\mathrm{N}_{\mathrm{F}}$ increases, while $\Delta T_{\mathrm{m}}$ changes

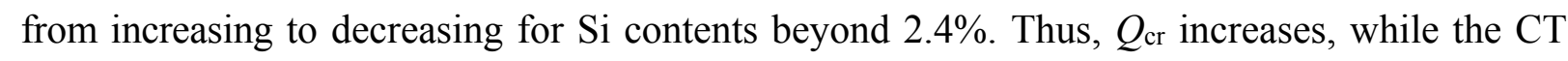
index and w both decrease.

- Manganese increases $N_{s}$ and $b$ and decreases $\mu$; consequently, it increases $\Delta T_{\mathrm{m}}$ and $N_{\mathrm{F}}$ and decreases $Q_{\mathrm{cr}}$, resulting in an increase in the CT and the w.

- Phosphorous increases $f$ and $\Delta T_{\mathrm{sc}}$ and decreases $\mu$ for the entire $\mathrm{P}$ content range. It also increases $N_{s}$ and b for up to $0.25 \% \mathrm{Si}$, and then, its effect diminishes. Consequently, there is an increase in $N_{\mathrm{F}}$ and $\Delta T_{\mathrm{m}}$, including $Q_{\mathrm{cr}}$, while the CT and the w both decrease.

- Sulfur increases $N_{s}$ and $b$ and decreases $\mu$; this leads to an increase in $\Delta T_{\mathrm{m}}$ and $N_{F}$ and a reduction in $Q_{\mathrm{cr}}$, resulting in an increase in the CT, as well as the w.

- Inoculation increases $N_{s}$ and $b$ and decreases $\mu$; consequently, inoculation decreases the $\Delta T_{\mathrm{m}}$ and increases $N_{F}$, leading to a decrease in the CT, as well as the $\mathrm{w}$.

- The time after inoculation decreases $N_{s}$ and $b$; consequently, $\Delta T_{\mathrm{m}}$ increases, while $N_{F}$ decreases over time, leading to a reduction in $Q_{\mathrm{cr}}$ and an increase in the CT, as well as the w.

\section{Acknowledgments}

The authors are grateful to Edward Fras from the University of Science and Technology in Krakow, Poland, who recently passed away. Fras has a long history of impressive contributions to the field of solidification, both in technical publications and in published books. 


\section{Author Contributions}

Hugo F. Lopez wrote and edited the paper and contributed to all activities. Marcin Gorny and Magdalena Kawalec performed the experiments and analyzed the results.

\section{Conflicts of Interest}

The authors declare no conflict of interest.

\section{References}

1. Fraś, E.; Górny, M.; Lopez, H. Graphite nodule and eutectic cell count in cast iron. Arch. Foundry Eng. 2007, 7, 47-52.

2. Fuller, A.G. Effect of superheating on chill and mottle formation. BCIRA J. Res. Dev. 1961, 9, 693-708.

3. Boyes, J.W.; Fuller, A.G. Chill and Motlle formation in cast iron. BCIRA J. Res. Dev. 1964, 12, 424-431.

4. Girshovitz, N. Solidification and Properties of Cast Iron; Mashinostroyene: Moscow-Leningrad, Russia, 1966. (In Russian)

5. Merchant, H.D. Solidification of cast iron. In Recent Research on Cast Iron, Gordon and Breach; Merchant, H., Ed.; Science Publishers: New York, NY, USA, 1968; pp. 1-100.

6. Dawson, J.V.; Maitra, S. Recent research on the inoculation of cast iron. Br. Foundrym. 1976, 4, 117-127.

7. Fraś, E.; Serrano, J.L.; Bustos, A. Fundiciones de Hierro; ILAFA: Valparaiso, Chile, 1990.

8. Kubick, E.J.; Javaid, A.; Bradley, F.-J. Investigation on effect C, Si, Mn, S and P on solidification characteristics and chill tendency of gray iron-Part II: Chill tendency. AFS Trans. 1997, 103, 579-586.

9. Oldfield, W. The chill-reducing mechanism of silicon in cast iron. BCIRA J. Res. Dev. 1962, 10, 17-27.

10. Hillert, M.; Subba Rao, V.V. Grey and white solidification of cast iron. In The Solidification of Metals; The Institute of Metals: London, UK, 1968; pp. 204-212.

11. Magnin, P.; Kurz, W. Competitive growth of stable and metastable Fe-C-X eutectic: Part I experiments. Metallurg. Trans. A 1988, 19, 1955-1963.

12. Frederiksson, H.; Svenson, I.L. Computer simulation of the structure formed during solidification of cast iron. In The Physical Metallurgy of Cast Iron; Fredrickson, H., Hillert, M., Eds.; North Holland: New York, NY, USA, 1985; pp. 273-284.

13. Nastac, L.; Stefanescu, D.M. Prediction of grey-to-white transition in cast iron by solidification modelling. AFS Trans. 1995, 103, 329-337.

14. Nastac, L.; Stefanescu, D.M. Modelling of stable-to-metastable structural transition in cast iron. In Physical Metallurgy of Cast Iron V; Lesoult, G., Lacaze, J., Eds.; Scitec Publications: Zürich, Switzerland, 1997; pp. 469-484.

15. Fras, E.; Górny, M.; López, H.F. The transition from grey to white cast iron during solidification: Part I. Theoretical background. Metallurg. Mater. Trans. A 2005, 36, 3007-3082. 
16. Magnin, P.; Kurz, W. An analytical model of irregukar eutectic growth and its application to Fe-C. Acta Metallurg. 1987, 35, 1119-1128.

17. Showman, R.E.; Aufderheide, R.C. A process for thin-wall sand castings. AFS Trans. 2003, 111, 567-578.

18. Midea, T.; Shah, J.V. Mold material thermophysical data. AFS Trans. 2002, 110, 121-136.

19. Popescu, M.; Thompson, J.; Zavadil, R.; Sahoo, M. Summary of AFS Research project on restoring techniques iron-phase I. AFS Trans. 2002, 110, 1047-1065.

20. Sommerfeld, A.; Tonn, B. Nucleation in cast iron. In Proceedings of the 5th Decennial International Conference on Solidification Processing, Sheffield, UK, 23-25 July 2007; pp. 467-471.

21. Goodrich, G.M.; Oakwood, T.G.; Gundlach, R.B. Manganese, sulfur and manganese-sulfur ratio effects in gray cast iron. AFS Trans. 2003, 111, 783-812.

22. Rys, J. Stereology of Materials; Fotobit: Krakow, Poland, 1995.

23. Osher, J.; Lorz, U. Quantitative Gefuengenanalysie; DVG Leipzig-Stuttgard: Frankfurt, Germany, 1994.

24. Doepp, R.; Schwenkel, S. Contribution to the influence of chemical composition and cooling conditions on the eutectic solidification of Fe-C-X melts. Mater. Sci. Eng. A 2005, 413, 334-338.

25. Kanno, T.; Kikuchi, T.; Kang, I.; Nakae, H. Effect of alloying elements on the eutectic temperature in cast iron. AFS Trans. 2005, 113, 825-833.

26. Neuman, F. The influence of additional elements on the physic-chemical behaviour of carbon in saturated molten iron. In Recent Research on Cast Iron; Gordon and Breach: New York, NY, USA, 1998; pp. 659-705.

27. Heine, R. The carbon equivalent Fe-C-Si diagram and its application to cast iron. AFS Cast Iron Res. J. 1971, 79, 49-54.

28. Fras, E.; Górny, M.; López, H.F. The transition from grey to white cast iron during solidification: Part II. Experimental verification. Metallurg. Mater. Trans. A 2005, 36, 3083-3092.

29. Juretzko, F.R.; Dix, L.P.; Ruxanda, R.; Stefanescu, D.M. Precondition of ductile iron melts for light weight casting: Effect on mechanical properties and microstructure. AFS Trans. 2004, 112, 773-785.

30. Fras, E.; Wiencek, K.; Górny, M.; López, H.F. Graphite nodule and eutectic count in cast iron, Theoretical model based on Weibull statistic and experimental verification. Metallurg. Mater. Trans. A 2007, 38, 385-394.

31. Fraś, E.; Górny, M.; López, H.F. Mechanism of carbon on the transition from graphite to eutectic cementite in cast iron. Metallurg. Mater. Trans. A 2014, 45, 5601-5612.

32. Fraś, E.; Górny, M.; López, H.F. Mechanism for the role of silicon on the transition from graphite to eutectic cementite in cast iron. Metallurg. Mater. Trans. A 2012, 43, 4204-4218.

33. Fraś, E.; Górny, M.; López, H.F. Role of Sulfur on the Transition from Graphite to Eutectic cementite in Cast Iron. Metallurg. Mater. Trans. A 2013, 44, 2512-2522.

(C) 2015 by the authors; licensee MDPI, Basel, Switzerland. This article is an open access article distributed under the terms and conditions of the Creative Commons Attribution license (http://creativecommons.org/licenses/by/4.0/). 